\title{
Using Simulated Dropsondes to Understand Extreme Updrafts and Wind Speeds in Tropical Cyclones
}

\author{
DANIEL P. STERN \\ University Corporation for Atmospheric Research, Monterey, California \\ GEORGE H. BRYAN \\ National Center for Atmospheric Research, Boulder, Colorado
}

(Manuscript received 5 February 2018, in final form 29 June 2018)

\begin{abstract}
Extreme updrafts $\left(\geq 10 \mathrm{~m} \mathrm{~s}^{-1}\right)$ and wind gusts $\left(\geq 90 \mathrm{~m} \mathrm{~s}^{-1}\right)$ are ubiquitous within the low-level eyewall of intense tropical cyclones (TCs). Previous studies suggest that both of these features are associated with coherent subkilometer-scale vortices. Here, over 100000 "virtual" dropsonde trajectories are examined within a large-eddy simulation (31.25-m horizontal grid spacing) of a category 5 hurricane in order to gain insight into the nature of these features and to better understand and interpret dropsonde observations. At such a high resolution, profiles of wind speed and vertical velocity from the virtual sondes are difficult to distinguish from those of real dropsondes. PDFs of the strength of updrafts and wind gusts compare well between the simulated and observed dropsondes, as do the respective range of heights over which these features are found. Individual simulated updrafts can be tracked for periods of up to several minutes, revealing structures that are both coherent and rapidly evolving. It appears that the updrafts are closely associated with vortices and wind speed maxima, consistent with previous studies. The peak instantaneous wind gusts in the simulations (up to $150 \mathrm{~m} \mathrm{~s}^{-1}$ ) are substantially stronger than have ever been observed. Using the virtual sondes, it is demonstrated that the probability of sampling such extremes is vanishingly small, and it is argued that actual intense TCs might also be characterized by gusts of these magnitudes.
\end{abstract}

\section{Introduction}

The eyewall of intense tropical cyclones (TCs) is often extremely turbulent (e.g., Lorsolo et al. 2010; Zhang et al. 2011a), particularly within the boundary layer, where the strongest wind speeds occur. The observational studies of Aberson et al. (2006) and Marks et al. (2008) showed that coherent kilometer-scale vortices can exist within the eyewall, and these vortices may be associated with localized extrema in both horizontal wind speed and vertical velocity. Recently, Stern et al. (2016, hereafter S16) presented a comprehensive dataset of extreme updrafts and wind speeds sampled by GPS dropsondes (hereafter, "sonde" is used interchangeably with "dropsonde") in the lower troposphere $(0-3 \mathrm{~km})$ within tropical cyclones. S16 found that updrafts exceeding $10 \mathrm{~ms}^{-1}$ are quite common within category 4 and 5 TCs and are nearly exclusively found within the eyewall, just inward of the radius of maximum

\footnotetext{
Corresponding author: Daniel P. Stern, dstern@ucar.edu
}

winds (RMW). Importantly, a substantial fraction of the sondes that sampled extreme updrafts also sampled wind speeds exceeding $90 \mathrm{~m} \mathrm{~s}^{-1}$, and S16 suggested that this is consistent with the hypothesis that these sondes are often sampling coherent vortices.

Since their introduction in 1997, GPS dropsondes (Hock and Franklin 1999) have been utilized in numerous studies of TCs (e.g., Franklin et al. 2003; Kepert 2006a,b; Zhang et al. 2011b; Zhang and Uhlhorn 2012; Richter and Stern 2014), as well as other atmospheric phenomena (e.g., Wakimoto et al. 2006; Wang et al. 2009). In particular, GPS dropsondes have substantially advanced our understanding of the TC boundary layer and of the maximum winds within TCs. For example, Franklin et al. (2003) used a composite of over 400 dropsondes to show that on average, the maximum winds in the eyewall are found near 500-m height, which is lower than had been suggested in previous observational studies (Marks and Houze 1987; Powell et al. 1991; Marks et al. 1992). Dropsondes have also been a critical tool for estimating the maximum surface wind 
speed, which is a key parameter for operational TC forecasting.

Dropsondes are sparsely distributed both in space and time, and there are typically only $4-8$ sondes dropped within the eyewall for an individual flight. Therefore, the strongest wind gusts are generally unsampled and therefore underestimated, although by how much is unknown. Another issue is that dropsondes are advected by the horizontal and vertical winds as they fall, and when dropped from a typical height of $2-3 \mathrm{~km}$ within the eyewall, the resulting horizontal drift can be substantial, sometimes $10-20 \mathrm{~km}$. Therefore, although dropsonde data are often visualized as vertical profiles, eyewall sonde trajectories are generally much more horizontal than vertical. This renders it quite challenging to interpret observed sonde profiles, as it can be unclear whether fluctuations are associated with vertical or horizontal variability. This problem is especially pronounced in regions of large horizontal gradients, such as the eyewall.

The purpose of this study is to use simulated dropsondes in order to better understand the observations of extreme updrafts and wind speeds presented by S16. Specifically, we seek to determine where such features are found and whether there is evidence for their association with coherent vortices, as well as the frequency with which they occur and are sampled and the implications this has for the strength of the peak wind gusts in real tropical cyclones. For this, we use an idealized largeeddy simulation and examine vertical velocity and wind speed profiles along simulated dropsonde trajectories. In section 2, we describe the modeling framework and virtual sonde sampling strategy. We evaluate the updraft and wind speed statistics for the virtual sondes in section 3 and compare to the observational dataset of S16. In section 4, we examine the evolution and structure of an individual updraft to gain insight into the type of features that dropsondes may be sampling. In section 5, we examine where extreme wind gusts and updrafts are found in the context of the mean eyewall structure, and we assess the probability that a given sonde or a combination of sondes will sample such extremes. In section 6 , we discuss how strong the strongest gusts in tropical cyclones may be in the context of existing observations. Finally, we present a summary and our conclusions in section 7 .

\section{Methodology}

Tropical cyclones are synoptic-scale vortices, with the circulation typically extending outward from the center by $1000 \mathrm{~km}$ or more. Therefore, in order to model an entire TC, a domain of at least several thousand kilometers on a side is required. At the same time, TCs are essentially composed of organized clusters of deep convection, and so in order to properly simulate the scales of motion relevant for TC intensity and structure, grid spacing on the order of $1 \mathrm{~km}$ is necessary (Fierro et al. 2009). Here, we are concerned with even smaller scales, of subkilometer vortices and boundary layer turbulence, which necessitates grid spacing of $100 \mathrm{~m}$ or less. It is currently computationally challenging to have grid spacing of $O(100) \mathrm{m}$ over a domain of thousands of kilometers in extent. We overcome this problem by using a large domain with a stretched grid, restricting the region of high resolution to a fine-mesh subdomain that is large enough to encompass the inner core of the TC, which is our area of interest. For the simulation we examine here, we use a total domain size of $3000 \mathrm{~km} \times$ $3000 \mathrm{~km}$, and the high-resolution portion of the domain is an $80 \mathrm{~km} \times 80 \mathrm{~km}$ square at the domain center. In this section, we give an overview of the modeling framework for this study; a more detailed description of this framework as applied to tornado simulations is given by Bryan et al. (2017a). For additional details, and results using this modeling approach for tropical cyclones, see Richter et al. (2016) and Worsnop et al. (2017a,b).

\section{a. LES framework}

We use Cloud Model 1 (CM1; Bryan and Fritsch 2002; Bryan and Rotunno 2009; Bryan and Morrison 2012) to simulate idealized tropical cyclones, with the model configured for large-eddy simulation (LES) using the technique described by Bryan et al. (2017a). In a central $80 \mathrm{~km} \times 80 \mathrm{~km}$ region, we use a constant horizontal grid spacing of $31.25 \mathrm{~m}$. In the lowest $3 \mathrm{~km}$, we use a constant vertical grid spacing of $15.625 \mathrm{~m}$. Outside of the central fine mesh, horizontal grid spacing increases gradually to $15 \mathrm{~km}$ at the domain boundary, and above $3 \mathrm{~km}$, vertical grid spacing increases gradually to $500 \mathrm{~m}$ at $8 \mathrm{~km}$ above sea level (ASL) and remains constant at $500 \mathrm{~m}$ until the model top at $25 \mathrm{~km}$ ASL. In the fine-mesh region, the large eddies that are responsible for most of the turbulent energy can be explicitly resolved, and no PBL scheme is used. However, because there is a transition from coarse to fine grid spacing, it takes time for realistic turbulence to develop within the inflow boundary layer in the fine-mesh region. If the flow is insufficiently turbulent in an LES, this can result in unrealistic boundary layer wind profiles (e.g., Markowski and Bryan 2016). Therefore, we add small-amplitude random perturbations to the potential temperature $\theta$ and water vapor mixing ratio $q_{v}$ fields in a $2-\mathrm{km}$-wide ring centered at $40-\mathrm{km}$ radius, as well as perturbations in the velocity fields (described below), in order to develop turbulence quickly within the inflow boundary layer. 
Within the fine-mesh region, we use a modified version of the "two part" LES subgrid model of Sullivan et al. (1994), which is based on the TKE scheme of Deardorff (1980); details are provided in the appendix of Bryan et al. (2017b). In the fine-mesh portion of the domain, the subgrid TKE is much smaller than the resolved TKE, except in the lowest two grid levels (not shown), indicating that large eddies are adequately resolved for our study. Outside of the fine-mesh region, we configure CM1 as a traditional mesoscale model and use a Louis PBL scheme (Louis 1979; Kepert 2012) to parameterize vertical turbulence processes, with a constant asymptotic mixing length $l_{\infty}=100 \mathrm{~m}$ (Zhang et al. 2011a; Bryan 2012). Horizontal diffusion is parameterized in the coarse-mesh portion of the domain with a mixing length $l_{h}$ that is a function of surface pressure $P_{\text {sfc }}$, which varies linearly from $100 \mathrm{~m}$ at $P_{\text {sfc }}=1000 \mathrm{mb}$ to $1000 \mathrm{~m}$ at $P_{\text {sfc }}=900 \mathrm{mb}(1 \mathrm{mb}=1 \mathrm{hPa})$.

Throughout the model domain, surface stress is parameterized through specification of a drag coefficient $C_{d}$, which increases linearly from $1 \times 10^{-3}$ to $2.4 \times 10^{-3}$ as the time-averaged $10-\mathrm{m}$ wind speed $U_{10}$ increases from 5 to $25 \mathrm{~m} \mathrm{~s}^{-1}$ and is constant above $25 \mathrm{~m} \mathrm{~s}^{-1}$. The surface heat and moisture flux transfer coefficients are constant, with $C_{h}=C_{q}=1.2 \times 10^{-3}$ (Drennan et al. 2007; Jeong et al. 2012). We use Morrison double-moment microphysics (Morrison et al. 2009) and do not parameterize convection or radiation. The SST is fixed at $28^{\circ} \mathrm{C}$, and we use a homogeneous background thermodynamic environment given by the Dunion (2011) moist tropical sounding, zero environmental wind, a constant Coriolis parameter of $f=5 \times 10^{-5} \mathrm{~s}^{-1}$, and doubly periodic lateral boundary conditions. A relaxation term is applied to velocities within $100 \mathrm{~km}$ of the lateral boundaries to damp gravity waves.

As described by Bryan et al. (2017a), the initialization procedure for the LES utilizes two types of precursor simulations. Because of the computational cost of the large-domain simulations, we first run an axisymmetric configuration of CM1 for several days in order to spin up a TC to the approximate desired intensity. The interpolated fields from this axisymmetric simulation provide the initial condition for the LES. We then run a separate smalldomain LES, following Bryan et al. (2017b), at the same resolution as the inner fine-mesh region of our primary simulation (i.e., $31.25-\mathrm{m}$ horizontal and $15.625-\mathrm{m}$ vertical grid spacing) in order to generate velocity perturbations that are "nudged" within the transition zone of the primary simulation throughout the length of the simulation. This "eddy injection" technique is described in detail by Bryan et al. (2017a) and allows for fully developed turbulence to "spin up" much closer to the edges of the fine-mesh portion of the domain.
For this study, our goal is to simulate an intense (so we can study the strongest gusts) and small (so the inner core can fit within the $80 \mathrm{~km} \times 80 \mathrm{~km}$ fine-mesh domain) TC. We ran the axisymmetric model for 12 days and took 48-h mean fields (from hourly output) centered on $t=11$ days to be the initial conditions for the largedomain LES (Fig. 1a). The maximum tangential velocity (at any height) is $89.7 \mathrm{~m} \mathrm{~s}^{-1}$. We then integrated the primary simulation for $4 \mathrm{~h}$, requiring about $500000 \mathrm{CPU}$ hours on the NCAR Yellowstone supercomputer (Computational and Information Systems Laboratory 2016). Figure $1 \mathrm{~b}$ shows the azimuthal-mean tangential velocity averaged over the fourth hour. Overall, the mean structure and intensity are similar to the initial fields, although a double wind maximum (in radius) forms from 3- to 8-km height that is not initially present. The cause of this double maximum is not clear; we note that it can also be seen in some idealized simulations in previous studies (e.g., Fig. 3e of Stern and Zhang 2013), though not (as far as we are aware) in existing observational analyses. As most of our analysis is focused on the lowest $2.5 \mathrm{~km}$ of the domain, we do not further investigate the double wind maximum in this study.

Figure $1 \mathrm{c}$ shows time series (every $15 \mathrm{~s}$ ) of the instantaneous maximum wind speed at the surface (i.e., $10 \mathrm{~m} \mathrm{ASL}$ ) and at any height. It can be seen that a statistically quasi steady state is reached very quickly, after only 10-20 min, and after this period, the initially smooth axisymmetric fields have become turbulent. The instantaneous peak wind speed is surprisingly large, generally $120-135 \mathrm{~m} \mathrm{~s}^{-1}$, and it is $105-120 \mathrm{~m} \mathrm{~s}^{-1}$ at the surface. After the initial spinup period, the peak gust (at any height) never falls below $117 \mathrm{~m} \mathrm{~s}^{-1}$ and occasionally exceeds $150 \mathrm{~m} \mathrm{~s}^{-1}$. Figure $1 \mathrm{~d}$ shows the maximum instantaneous surface wind speed over the previous minute (from each model time step every $0.1875 \mathrm{~s}$ ), and this time series (every $1 \mathrm{~min}$ ) indicates that even at the surface, wind speeds sometimes exceed $130 \mathrm{~m} \mathrm{~s}^{-1}$. At first, these values may seem unrealistic, as these speeds are substantially greater than have ever been observed in a TC. However, the conventional metric for TC intensity is the maximum of an average wind speed, which in the United States is taken to be a 1-min mean. The peak 1-min mean surface wind speed is near $80 \mathrm{~m} \mathrm{~s}^{-1}$ (Fig. 1d), which, although very intense, is realistic for a category 5 hurricane [comparable to the peak intensities of, e.g., Mitch (1998), Katrina (2005), Wilma (2005), Dean (2006), and Felix (2007)]. Below, we use simulated dropsondes to show that the extreme instantaneous wind gusts in the simulation are actually plausible, as undersampling makes it likely that peak wind gusts in actual TCs are substantially underestimated. 

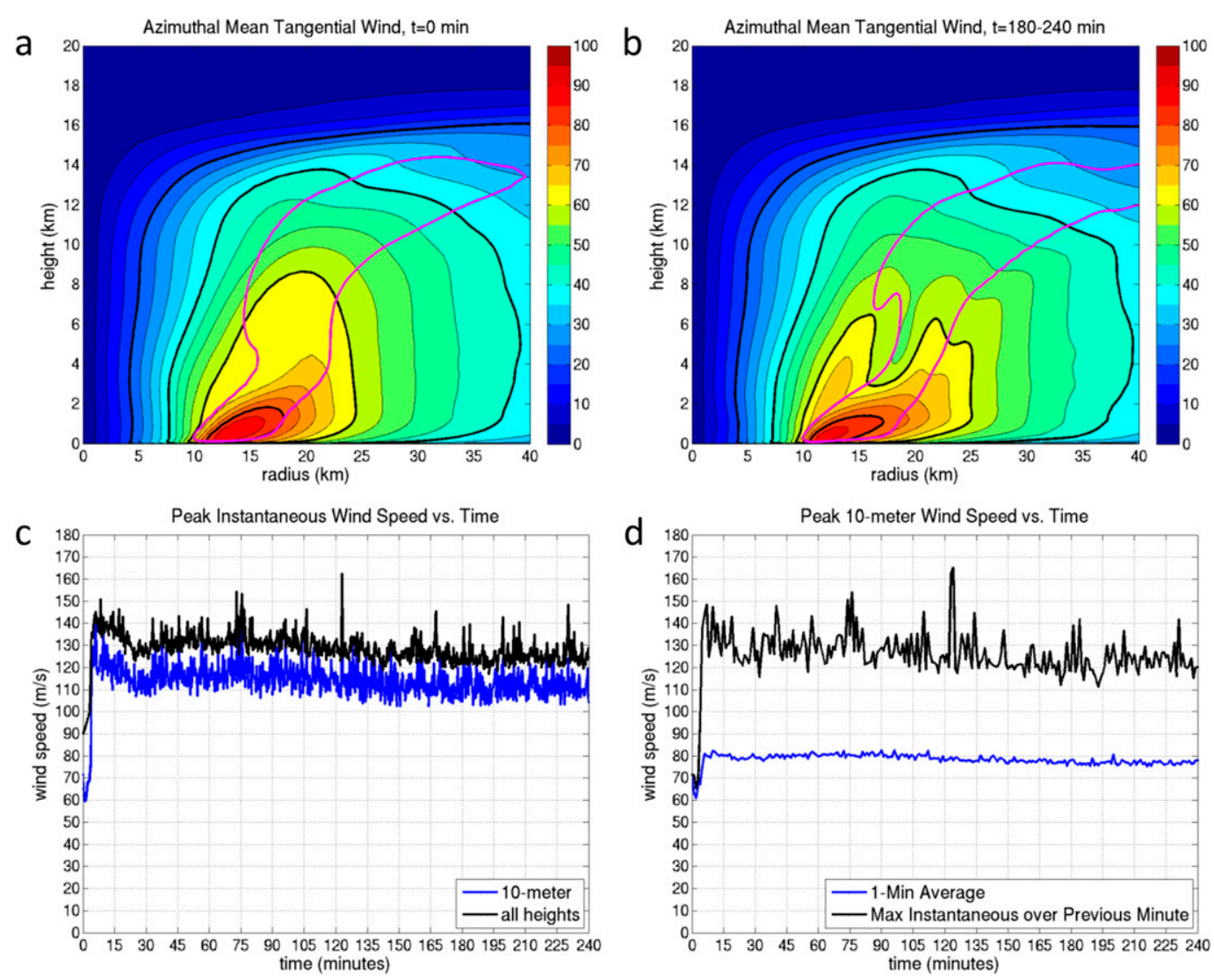

FIG. 1. (top) Azimuthal-mean tangential wind at $t=$ (a) 0 and (b) 180-240 min (averaged from 1-min data) for the LES. The azimuthal-mean eyewall updraft $\left(1 \mathrm{~m} \mathrm{~s}^{-1}\right.$ contour) is shown in magenta. (bottom) Time series of (c) the maximum instantaneous wind speed (at 10-m height and all heights) and (d) the global peak of the time mean and instantaneous wind speeds over the previous minute at 10-m height. Data in (c) and (d) are plotted every $15 \mathrm{~s}$ and $1 \mathrm{~min}$, respectively. Note that in (d), the maximum is taken over all model time steps within each 1-min period, and so this represents the true simulated maximum surface wind speed.

As noted above, in this study, our focus is on peak instantaneous wind speeds, which we refer to as extreme wind "gusts." Technically, a gust is defined as the peak wind speed over a given averaging period at a fixed point, within some defined longer time interval (Harper et al. 2010). For example, the peak 3-s wind speed within a 10-min period is often used. Because we are evaluating dropsondes (both observed and simulated), which provide a semi-Lagrangian and nearinstantaneous ${ }^{1}$ measurement of the wind (Franklin et al. 2003), it is simplest and most appropriate to evaluate the instantaneous winds within this simulation. Nevertheless,

\footnotetext{
${ }^{1}$ Though dropsondes typically sample the wind speed at 2 or $4 \mathrm{~Hz}$, Franklin et al. (2003) note that the actual measurements are made "on the order of milliseconds." For observations, filtering (with a cutoff wavelength of 5 or $10 \mathrm{~s}$ ) is typically applied during postprocessing, but the resulting change in peak wind speed is small because the sondes are moving with the winds.
}

it is worthwhile to briefly examine 3-s wind speeds within our simulation, as this will allow for some comparison to in situ observations (which often use such an averaging period) in section 6 . Figure 2 a shows for a 10 -min period (starting at $t=265 \mathrm{~min}$ ) the peak surface wind speed, evaluated instantaneously and for 3-s and 1-min averages. The peak instantaneous wind speed is typically 10 $15 \mathrm{~m} \mathrm{~s}^{-1}$ greater than the peak 3-s wind speed, with occasional differences of $25-30 \mathrm{~m} \mathrm{~s}^{-1}$. Though substantial, these differences between the peak instantaneous and peak 3-s gusts are much less than seen in the tornado simulations evaluated by Nolan et al. (2017) (such differences there occasionally exceed $100 \mathrm{~m} \mathrm{~s}^{-1}$ ). As we will later show, the horizontal scale of the features producing extreme gusts in our simulation is on the order of $500 \mathrm{~m}$, and so a fixed point would typically experience such a feature over a period greater than $3 \mathrm{~s}$, which is why instantaneous and 3-s gusts are apparently more similar for hurricanes than for tornadoes. Finally, it is of interest to 

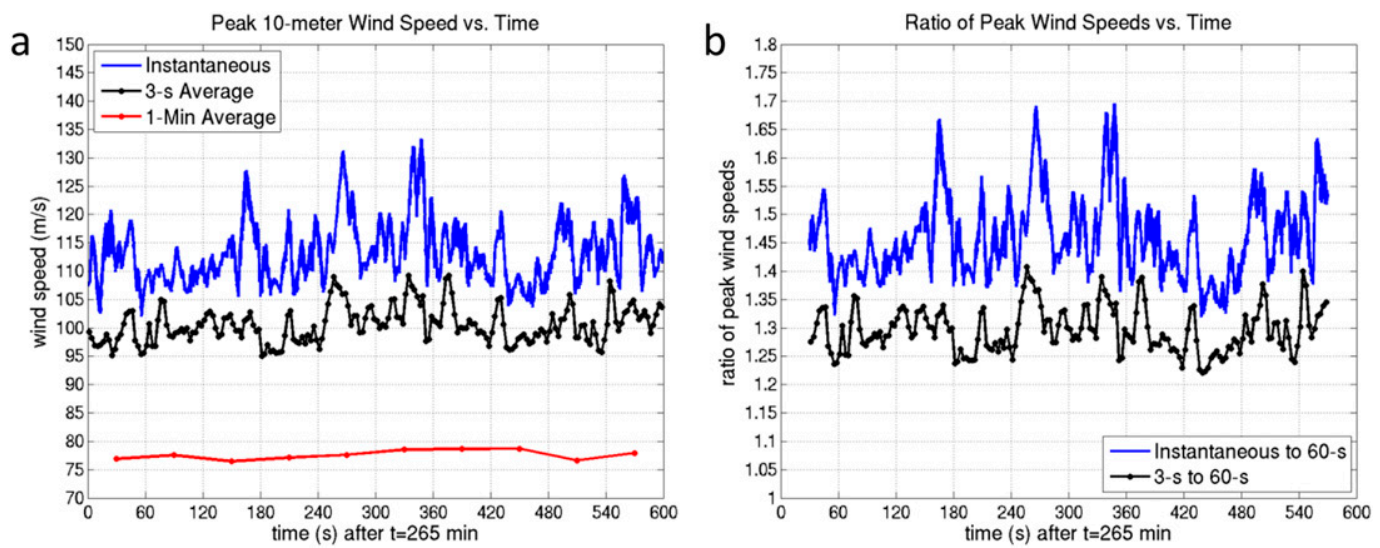

FIG. 2. (a) Time series of the maximum wind speed at 10-m height, from the instantaneous, 3-s average, and 1-min average fields. The instantaneous wind speed is given at every model time step $(0.1875 \mathrm{~s})$, and the 3-s and 1-min wind speeds are given at their respective averaging periods using a centered average. (b) Time series of the ratios of the peak instantaneous and peak 3-s wind speed to the peak 1-min wind speed at 10-m height. Both plots are for a 10 -min period, beginning at $t=265 \mathrm{~min}$.

know the expected peak gusts for a given 1-min maximum wind speed, and so Fig. $2 \mathrm{~b}$ shows the ratio of the peak instantaneous and 3-s wind speeds to the peak 1-min wind speed. ${ }^{2}$ On average, the respective ratios are 1.46 and 1.30 ; this latter value is somewhat higher than the factor of $1.20-1.25$ used operationally by NHC (J. Cangialosi 2016, personal communication).

\section{b. Dropsondes in CM1}

CM1 includes the capability to compute parcel trajectories within the model integration using a secondorder Runge-Kutta time-integration scheme and trilinear interpolation. By modifying the vertical velocity used to transport parcels by adding a fall speed, we can simulate dropsonde trajectories in a realistic manner. Except for the fall speed, we are considering the dropsondes to be passively advected by the local resolved winds. Although dropsondes have inertia and so their horizontal velocities can differ from the wind velocity, this difference is generally quite small ( $\mathrm{Li}$ and Miller 2014), so for our purposes, we can neglect this effect. ${ }^{3}$ Note that for observed

\footnotetext{
${ }^{2}$ Note that this metric is not actually a traditional "gust factor," which is the ratio of the peak gust to the mean wind speed at a specific location. Instead, Fig. $2 \mathrm{~b}$ shows the ratios of the global peak wind speeds of different averaging periods (and that may be found at differing locations). For an evaluation of true gust factors within this simulation, see Worsnop et al. (2017a).

${ }^{3}$ When the air velocity experienced by a sonde varies rapidly in time, the resulting large sonde-relative winds are short-lived because the horizontal acceleration of the sonde is also large [see (A6) of Hock and Franklin (1999)], given the characteristics of the RD94 dropsondes. Therefore, it is difficult for such a sonde to deviate substantially in horizontal trajectory from that of a (falling) massless particle.
}

sondes, the postprocessed winds are generally retrieved from the dropsonde velocity by application of the "wind finding" equations, as presented by Hock and Franklin (1999). In our simulation, we know the "true" winds at the location of the simulated dropsonde, so no such correction is necessary.

The theoretical terminal fall rate of a dropsonde is given by (Hock and Franklin 1999)

$$
w_{\text {fall }}=\left[2 m_{s} g /\left(C_{d s} A_{s} \rho\right)\right]^{1 / 2},
$$

where $m_{s}$ is the sonde mass, $g$ is the gravitational acceleration, $C_{d s}$ is the drag coefficient of the sonde, $A_{s}$ is the cross-sectional area of the parachute, and $\rho$ is the density of the air. The current generation Vaisala RD94 dropsonde weighs $322 \mathrm{~g}$ and has a parachute area of $0.09 \mathrm{~m}^{2}$ and a nominal drag coefficient of 0.61 , which yields a near-surface fall speed of $10-12 \mathrm{~m} \mathrm{~s}^{-1}$. We use (1) along with the RD94 parameters and the simulated air density to calculate the fall speed of the simulated sondes, which is added to the vertical velocity of the air for the purpose of trajectory integration. This procedure occurs at every time step. Finally, we output diagnostic variables along the trajectories by interpolating model fields (including air velocity) to the sonde positions.

\section{c. Observed versus virtual sonde sampling strategy}

For a typical operational hurricane reconnaissance flight, a "figure four" or "alpha" pattern is executed, which involves two orthogonal passes through the center, yielding four radial legs, usually along intercardinal tracks that extend outward to $105 \mathrm{~nm}(196 \mathrm{~km})$ from the TC center. According to the protocol of the National Hurricane Operations Plan (NHOP; OFCM 2017), 
a sonde should be dropped at the location of the flightlevel TC center (as determined by the wind speed minimum) found during each pass, as well as within the eyewall during each inbound and outbound leg; this procedure yields two eye sondes and four eyewall sondes per figure-four pattern. If aircraft range allows, two figure-four patterns can be executed in a single flight, resulting in eight eyewall sondes over a period of about $5 \mathrm{~h}$ (Uhlhorn and Nolan 2012). NHOP also mandates that the eyewall sondes should be released "at or just inward (within $12 \mathrm{~km}$ ) of the flight-level radius of maximum wind," noting that the inner edge of the radar eyewall can also be used as the drop location. Flight level varies with storm intensity, but for hurricane-strength TCs is usually $700 \mathrm{mb}$. Compared to the operational Air Force (AF) flights, the sampling strategy for NOAA research flights is more varied, and for some storms there can be a dozen or more eyewall sondes released during a single flight. Nevertheless, for most flights, there is a general goal to drop a single sonde just inward of the flight-level RMW on each inbound and outbound leg, and the total number of sondes that might potentially sample the strongest wind gusts remains limited. With present-day observations alone, it is not possible to determine how these sampling procedures affect observational measurements of peak wind speed in TCs.

In our simulations, we can release many thousands of virtual dropsondes at any location and any time. Partly for convenience, and to reduce computational cost, we choose to simultaneously release all virtual dropsondes for our analyses in this study. This is obviously unrealistic from an observational standpoint, but because our simulated TC is statistically steady, there is unlikely to be a systematic difference between simultaneous sampling and sequential sampling within the simulation. A primary goal of this study is to generate estimates of the probabilities of sampling extreme wind gusts, and this goal is facilitated by using very large sample sizes. Further, we can subsample our resulting dataset of virtual sondes in order to estimate the likelihood of sampling extreme wind gusts for an observed TC.

\section{Evaluating the virtual sondes}

Figure 3 shows horizontal cross sections of the instantaneous, 3-s mean, and 1-min mean 10-m wind speed at $t=266 \mathrm{~min}$. Although there are numerous small-scale features with instantaneous wind speed exceeding $90 \mathrm{~m} \mathrm{~s}^{-1}$ (Fig. 3a), the 1-min mean wind speed field is relatively smooth (Fig. 3c), and the peak 1-min mean wind speed is only $77 \mathrm{~m} \mathrm{~s}^{-1}$. This is consistent with the time series in Fig. 1 and the results of Rotunno et al. (2009)
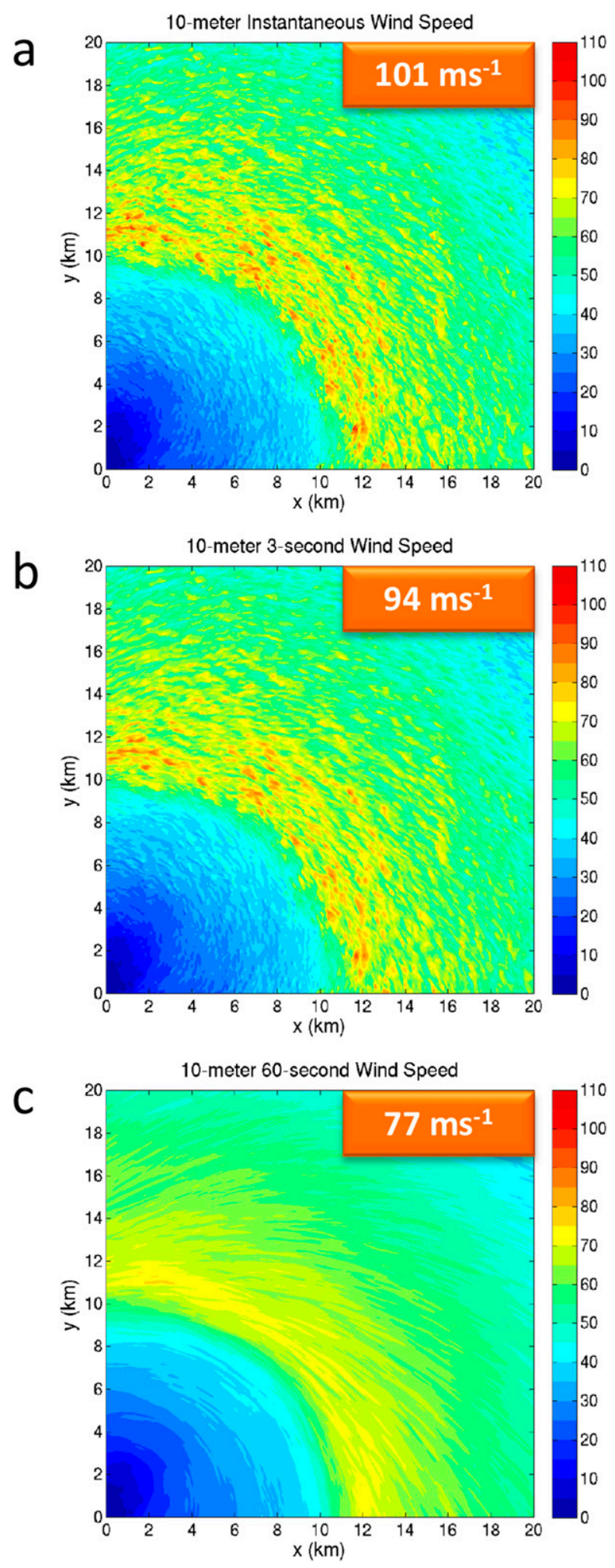

FIG. 3. (a) Instantaneous, (b) 3-s mean, and (c) 1-min mean wind speeds at $10-\mathrm{m}$ height at $t=266 \mathrm{~min}$. The respective maximum values within this $20 \mathrm{~km} \times 20 \mathrm{~km}$ box are indicated in each panel (the domain maxima may exceed these values). Note that the simulated dropsondes shown in subsequent figures were released at $t=250 \mathrm{~min}, 16 \mathrm{~min}$ prior to the time of the wind speed field shown here. 
and underscores the fact that in this study, we are primarily examining instantaneous gusts, which are not representative of the mean winds that are conventionally used to define TC intensity. The paths of local extreme gusts can be seen in the 1-min mean field (Fig. 3c) as streaks of higher wind speed, which are approximately aligned with the surface wind direction (not shown).

We also examined the 3-s mean wind speed (Fig. 3b), as this averaging period is conventionally used by the wind engineering community. The 3 -s and instantaneous winds are very similar in structure and, at most locations, differ little in magnitude. It is only the most extreme gusts for which the 3-s average wind speed is substantially weaker than the instantantaneous wind speed. Except where indicated otherwise, all of the following analyses are based on the instantaneous wind speed. Note that although the 3-s period is commonly used for relating wind speed to structural damage, this convention is based on the properties of anemometers, and the most physically relevant averaging period for relating wind speed to damage is unknown (Dahl et al. 2017).

The sondes are released in a $321 \times 321$ grid (103041 sondes) every $250 \mathrm{~m}$ in $x$ and $y$ (every eighth grid point), centered on the middle of the domain. For Fig. 3, we show only the northeast quadrant over a $20 \mathrm{~km} \times 20 \mathrm{~km}$ box, though the sondes are released throughout the $80 \mathrm{~km} \times 80 \mathrm{~km}$ LES subdomain. Although observational missions usually fly along constant pressure surfaces, for simplicity, we release the virtual sondes at constant height, and there is no reason to expect that this choice will have a systematic effect on our analyses. We chose a release height of $2500 \mathrm{~m}$ ASL, which is within the typical range of 700-mb heights for the eyewall region of intense hurricanes.

In this section, we aim to use the virtual dropsondes to demonstrate that the simulation compares reasonably well with observations. Toward this goal, in Fig. 4, we show vertical velocity versus height for nine different dropsondes. Eight of these dropsondes are simulated, and they are chosen because they happen to have similar peak updrafts at similar heights as those of the other sonde, which is a real dropsonde released within Hurricane Isabel (2005). We would suggest that it is quite challenging to determine from these vertical velocity profiles which one is from the real dropsonde. ${ }^{4}$ Figure 5

\footnotetext{
${ }^{4}$ The real sonde is plotted in Fig. 4h. The only apparent visual difference between this profile and the others is that only this profile does not smoothly terminate at $w=0 \mathrm{~m} \mathrm{~s}^{-1}$ at the surface. Zero vertical motion is an enforced boundary condition in the model, but the real ocean has waves, and for this and other reasons (including instrument errors), the observed vertical velocity need not be zero.
}

shows the profiles of horizontal wind speed for the same sondes as in Fig. 4. As with vertical velocity, the real dropsonde wind speed data are difficult to distinguish from the simulated dropsonde wind speed data. Overall, there is good qualitative agreement between the simulated and observed sonde profiles. This lends some confidence to our simulation and in particular to the realism of the representation of the turbulent boundary layer and the structures that result in extreme wind gusts and updrafts within the eyewall.

\section{a. Comparison of simulated and observed magnitudes of peak updrafts and wind speeds}

Figure 6 shows PDFs of the maximum vertical velocity and maximum wind speed for the virtual sondes and for the observed dropsondes from the dataset of S16. The S16 dataset contains all NOAA and AF dropsondes from 1997 to 2013 that sampled updrafts of $\geq 10 \mathrm{~m} \mathrm{~s}^{-1}$ (termed w10) or wind speeds (ws) $\geq 90 \mathrm{~m} \mathrm{~s}^{-1}$ (termed ws90). Therefore, for our simulation, the PDF of maximum vertical velocity in Fig. 6a is taken from the subset of virtual sondes that sample $w \geq 10 \mathrm{~m} \mathrm{~s}^{-1}$, and the PDF of maximum wind speed in Fig. $6 \mathrm{~b}$ is taken from the subset that sample ws $\geq 90 \mathrm{~m} \mathrm{~s}^{-1}$. Because the sample sizes are much larger for the simulation, we randomly sample the simulated sondes using the respective observed sample sizes and repeat this 10000 times to generate a mean PDF along with the $90 \%$ confidence interval. For both vertical velocity and wind speed, the most extreme sampled values are of similar magnitude between the simulation (Figs. 6a,b) and observations (Figs. 6c,d). The frequency of values in a given bin decreases monotonically with magnitude in the simulation and nearly so in the observations (with the irregularities indicative of the much more limited observation sample size). There is a sharper dropoff in the observed distribution, with approximately twice as many samples in the lowest bin $\left(w=10-12 \mathrm{~m} \mathrm{~s}^{-1}\right.$, ws $\left.=90-92 \mathrm{~m} \mathrm{~s}^{-1}\right)$ for the observed dropsondes as compared to the virtual dropsondes, and a Kolmogorov-Smirnov test indicates that the observed and simulated distributions are significantly different.

It is difficult to definitively determine the reason for the differences between the observed and simulated PDFs. With the caveat that it is possible that these differences are due to either model or observational biases, there are two other potential explanations that we suspect are more likely. In the simulation, the shapes of the PDFs vary for different subset radial ranges (not shown). As shown by S16, most observed ws 90 and w10 sondes were dropped between 0 and $10 \mathrm{~km}$ inward of the flight-level RMW, and this is true for the simulated 

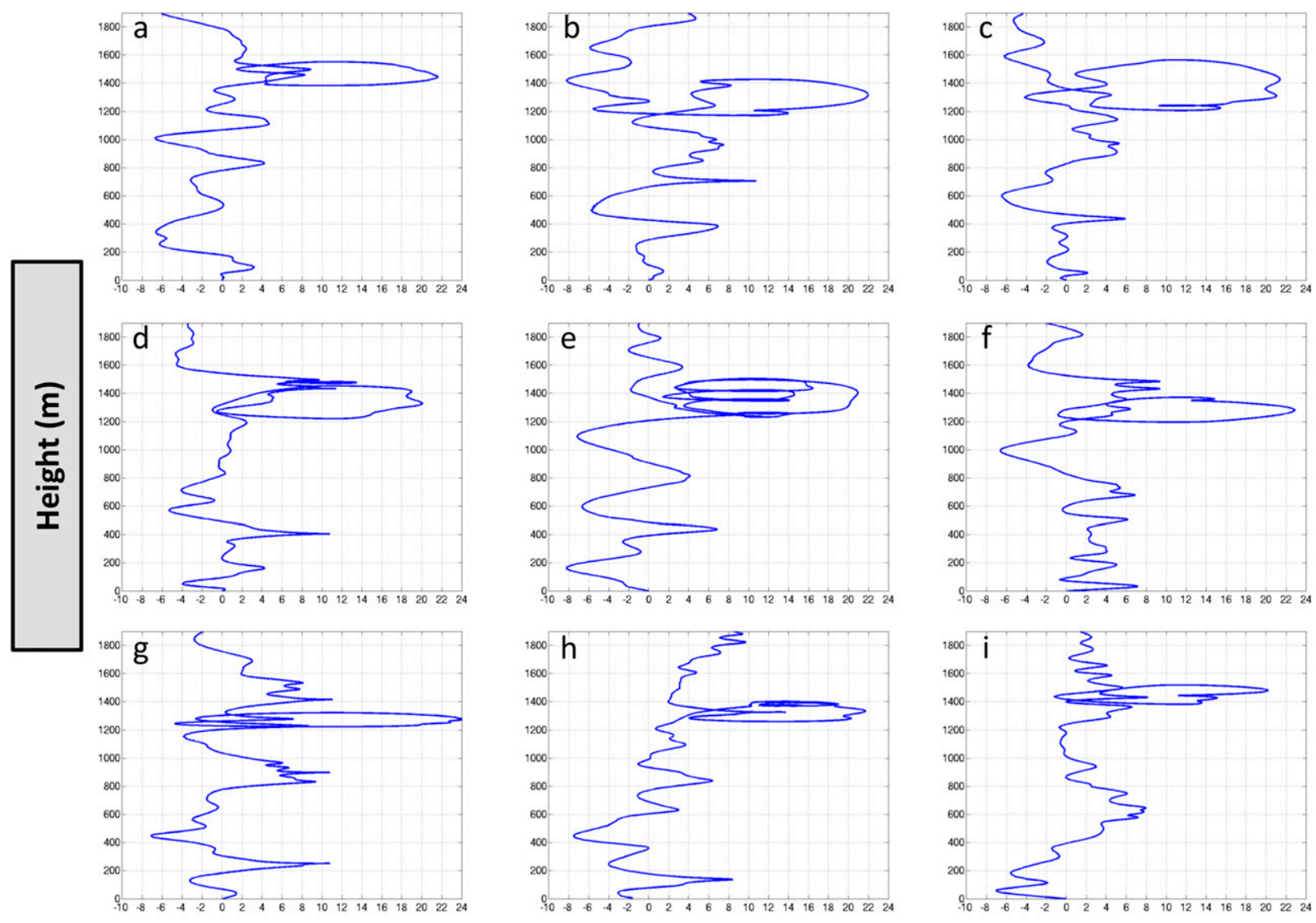

\section{Vertical Velocity $(\mathrm{m} / \mathrm{s})$}

FIG. 4. Vertical velocity vs height for eight virtual dropsondes and one real dropsonde (Hurricane Isabel at 1752:48 UTC 13 Sep 2003). For this comparison, virtual sondes were selected based on their overall resemblance to the structure of the real profile in terms of the maximum updraft and the height at which it occurs. The virtual sondes were all released at $z=2500 \mathrm{~m}$, but only the lowest $1900 \mathrm{~m}$ of the profiles are shown to aid in comparison to the observed sonde.

sondes as well. However, given the limited observational sampling and uncertainties in the representativeness of the local flight-level RMW, it is possible that differences between the observed and simulated PDFs are related to radial sampling differences along with the systematic variation of the distribution of extremes with radius relative to the RMW.

It is also possible that this difference in the PDFs is a consequence of differences between the intensity of the simulated TC and the typical intensities represented in the S16 datasets. From comparisons of other simulations (not shown), it is apparent that relatively small differences in the mean intensity can lead to large shifts in the tail of the PDF. The best track intensity of the observed ws 90 sondes of S16 ranges from 130 to $160 \mathrm{kt}$ $\left(1 \mathrm{kt} \approx 0.51 \mathrm{~m} \mathrm{~s}^{-1}\right)$, with a median and mean of about 140 and $145 \mathrm{kt}$, respectively. We assess that a representative 1 -min mean intensity of the simulation is approximately $150-155 \mathrm{kt}$. Though this is not that different from the mean observed intensity, it is possible that the true mean intensity of the observed TCs with ws 90 sondes is somewhat weaker than the simulated TC. Though the observed extreme updrafts are overwhelmingly from strong hurricanes (S16), the median (and mean) best track intensity for the w10 dataset is $125 \mathrm{kt}$, substantially lower than that of our simulated storm. It is likely that the frequency of both extreme wind speeds and updrafts increases with TC intensity (based on the results of S16), and we suspect that the mean intensity difference is the primary cause of the differences between the observed and simulated PDFs. Because of this sensitivity, the comparison of the distribution of magnitudes of extremes between the S16 observations and a simulation such as this one is ultimately only useful for validating the accuracy of the model in a broad qualitative sense. 

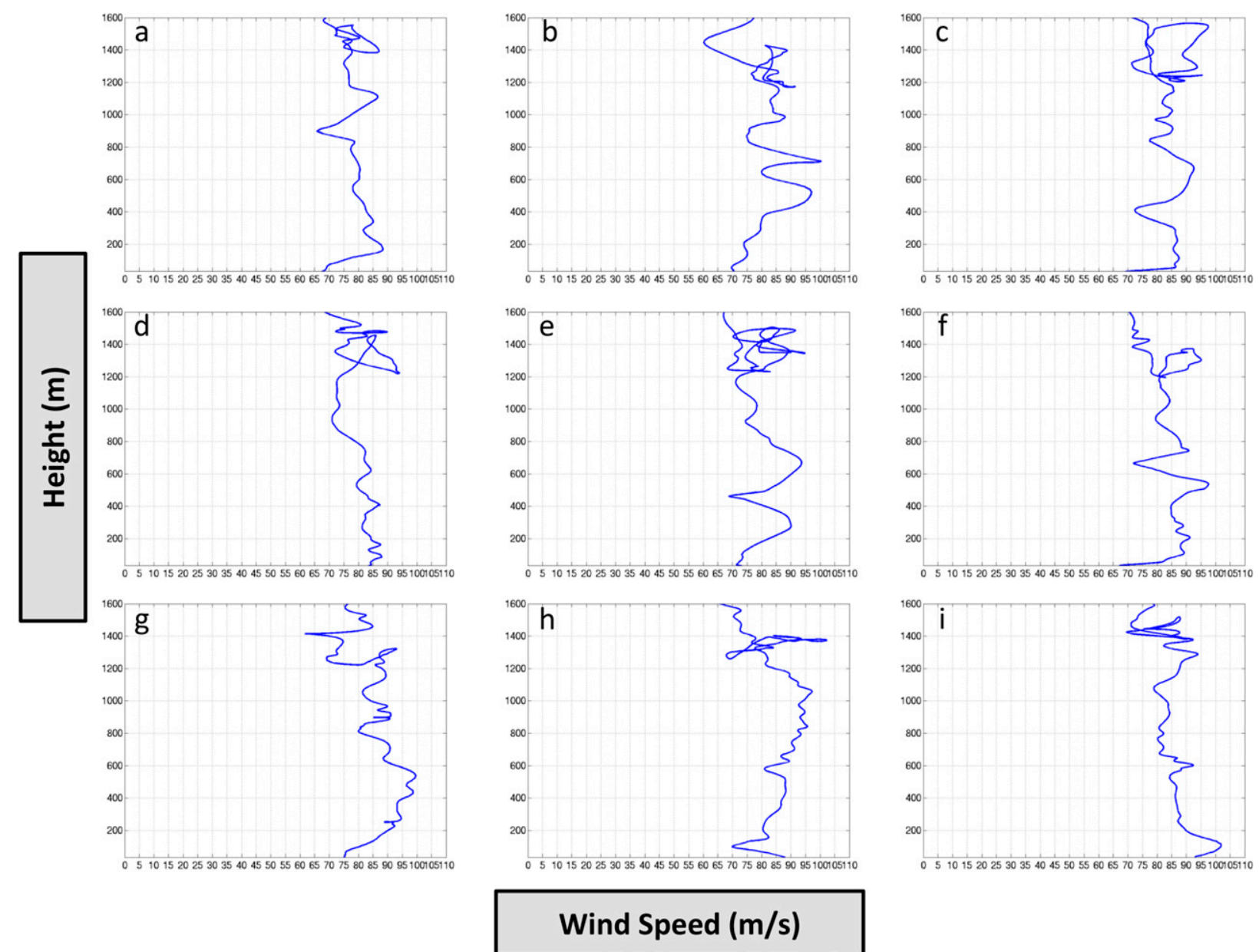
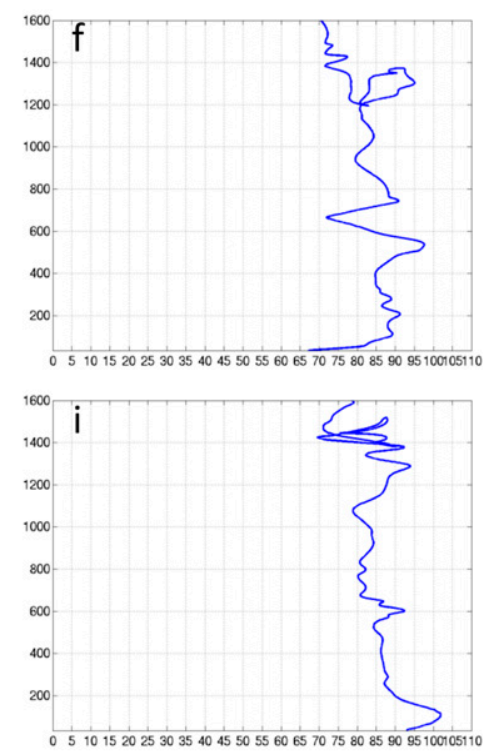

FIG. 5. As in Fig. 4, but for wind speed. The height range shown $(z=34-1600 \mathrm{~m})$ is different from Fig. 4 in order to correspond to the data coverage of wind speed for the observed sonde.

\section{b. Comparison of simulated and observed heights of peak updrafts and wind speeds}

Figure 7 shows the heights of maximum vertical velocity and maximum wind speed for the virtual sondes, along with the respective heights from the S16 observational dataset. There is relatively good agreement between the simulated and observed heights of the w10 updrafts, in that extreme updrafts are sampled with similar frequencies at any height below the release point, including within the lowest $500 \mathrm{~m}$. The peak updrafts are most frequently found from 2000 to $2500 \mathrm{~m}$ in the simulation, as opposed to $500-1000 \mathrm{~m}$ in the observations. It is possible that this represents a meaningful difference, but this could also reflect radial differences in sampling. Again, a qualitative evaluation of the simulated sondes is most appropriate, and in this sense, the distribution of heights of extreme updrafts is in good agreement between the simulation and the observations.
The height of maximum wind speed for observed ws 90 sondes has a relatively strong peak at $400-600 \mathrm{~m}$, although the maximum wind speed is sometimes found even within the lowest $200 \mathrm{~m}$ above the surface. The existence of extreme wind speeds within the lowest $200 \mathrm{~m}$ is also seen for the simulated sondes, and the peak of the distribution is found at similar heights, though slightly lower (200-400 m) for the simulated ws 90 sondes. The PDF of heights is substantially broader for the simulation; there are no observed ws 90 sondes with the maximum wind speed found above $1400-\mathrm{m}$ height, whereas about $10 \%$ of the simulated ws 90 sondes have maxima above this height. As with the w10 sondes, differences in sampling location may play a role in the differences in these heights. However, a larger influence is likely the sensitivity of the height of extreme gusts to the threshold value of wind speed. Figure 8 shows the distribution of heights of the peak simulated gusts, but for speeds exceeding 100 and $110 \mathrm{~m} \mathrm{~s}^{-1}$, respectively. 

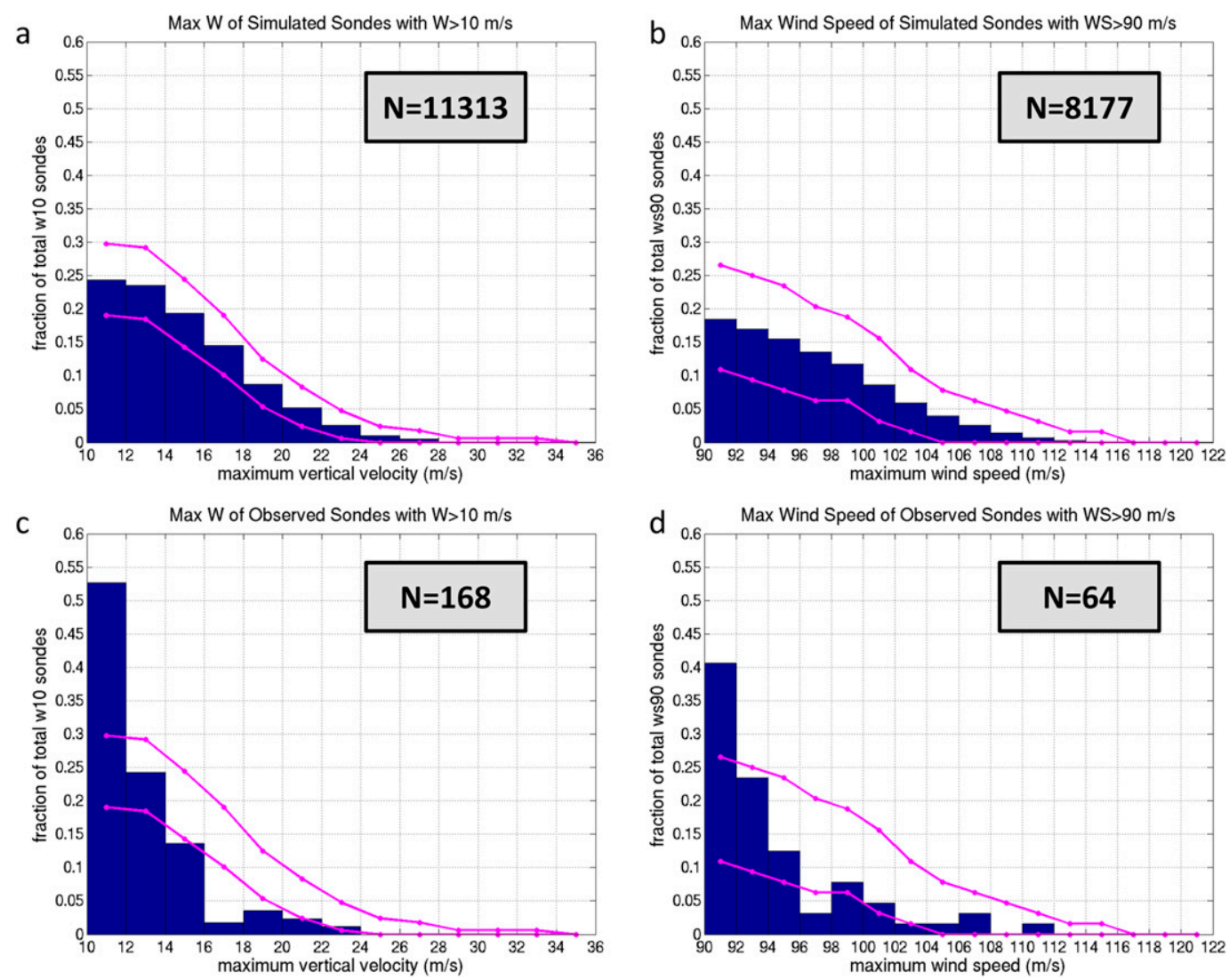

FIG. 6. PDFs of (left) maximum vertical velocity for the w10 sondes and (right) maximum wind speed for the ws 90 sondes. (a),(b) Simulated and (c),(d) observed sondes. The total number of sondes is given in each respective panel. The simulated PDFs represent the mean of 10000 random samples from the simulated w10 and ws 90 sondes, using the respective observed sample sizes. The magenta lines show the 5th and 95th percentiles of the respective simulated PDFs, and these are overlaid on both the mean simulated and the observed PDFs.

Comparing Fig. $7 \mathrm{~b}$ to Figs. $8 \mathrm{a}$ and 8 b, it can be seen that the distribution of heights narrows as the threshold wind speed increases; for example, there are no simulated sondes that sample gusts exceeding $110 \mathrm{~m} \mathrm{~s}^{-1}$ above $1200-\mathrm{m}$ height. As we will later show, the strongest simulated gusts are indeed confined to the lowest 500 $1000 \mathrm{~m}$. That the peak wind speeds for the ws 90 sondes are found at greater heights in the simulation than in the observed sondes likely indicates that the simulated storm is indeed somewhat more intense than the mean observed storm, consistent with the above comparison of best track intensities. Finally, note that in both the simulation and the observations, the strongest updrafts are found over a much deeper layer than the strongest wind speeds.

\section{What features are the dropsondes sampling?}

From the observed dropsondes alone, it is not possible to reliably determine the type of features that the dropsondes are sampling. This is for two reasons: a given feature is rarely, if ever, sampled by more than one sonde, and the sonde moves with the local horizontal wind as it falls relative to the local vertical wind. As discussed by S16, because an eyewall sonde trajectory is generally much more horizontal than vertical, what may appear to be vertical variations in kinematic and thermodynamic structure can actually be the aliasing of horizontal variability onto the vertical. In spite of these difficulties, in S16, we hypothesized that some of the sondes that sampled extreme updrafts or wind gusts had encountered coherent vortices along the inner edge of the eyewall. In our simulation, we can examine the structure of the features that exhibit these extremes. Here, we present an example of one such feature to illustrate the simulated structures. We have examined other individual updrafts in this simulation, as well as composites over many updrafts in preliminary coarser simulations (not shown), and we believe that the basic structural relationships shown in this example are 

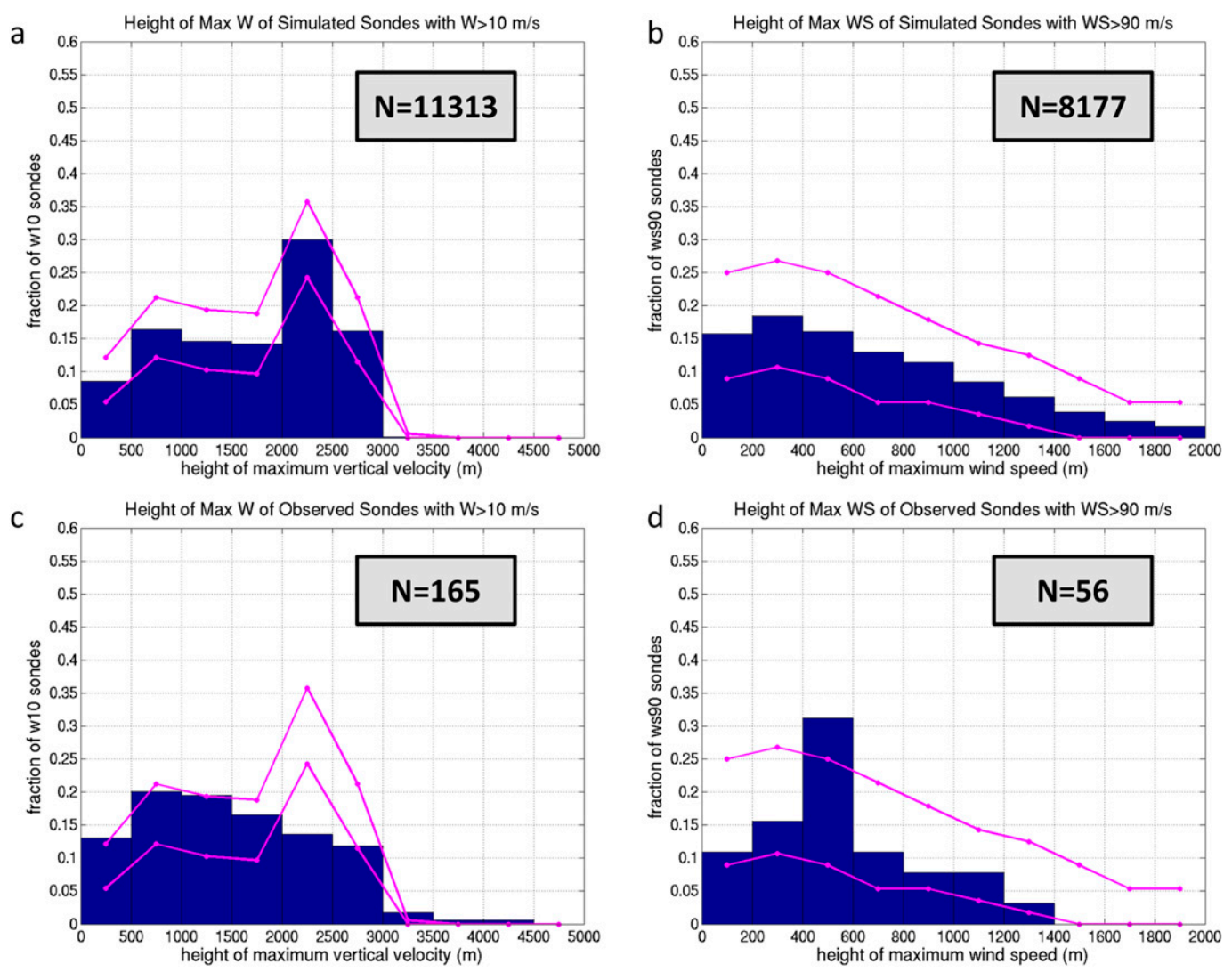

FIG. 7. As in Fig. 6, but for the heights where the respective maxima occur. Note that the bin sizes and height ranges shown differ between the w10 and ws 90 sondes. The observational sample size is slightly different from that in Fig. 6 because some sondes have no height data.

broadly representative. A more comprehensive investigation will be presented in a future study.

Figure 9a shows the horizontal tracks of updrafts at approximately 200-m height that exceed a threshold of $15 \mathrm{~m} \mathrm{~s}^{-1}$ at a chosen initial time. All distinct updrafts from this single initial time that can be tracked and continuously exceed $15 \mathrm{~m} \mathrm{~s}^{-1}$ for at least $30 \mathrm{~s}$ are shown. In this example, there are 62 such features, with the longest trackable duration being $162 \mathrm{~s}$. On average, these updrafts move radially inward at $12 \mathrm{~m} \mathrm{~s}^{-1}$ while translating azimuthally at $74 \mathrm{~m} \mathrm{~s}^{-1}$, and the rate of inward propagation slows down as the updrafts approach the inner edge of the eyewall, consistent with the azimuthal-mean structure of the boundary layer inflow (not shown).

Figure $9 \mathrm{~b}$ shows the time series of maximum vertical velocity for the updraft that becomes the strongest among the tracked features (shown in magenta in Fig. 9a). Within a 2-min period, this updraft undergoes three distinct cycles of intensification and weakening, including an increase from 24 to $45 \mathrm{~m} \mathrm{~s}^{-1}$ over only $20 \mathrm{~s}$. Also shown in Fig. 9b is the minimum vertical velocity within a $500 \mathrm{~m} \times 500 \mathrm{~m}$ box around the location of the peak updraft. A very strong downdraft develops during this period, reaching speeds exceeding $20 \mathrm{~m} \mathrm{~s}^{-1}$. Also associated with the updraft is a local maximum in horizontal wind speed, with a peak of $118 \mathrm{~m} \mathrm{~s}^{-1}$ and exceeding $100 \mathrm{~m} \mathrm{~s}^{-1}$ nearly continuously for about $100 \mathrm{~s}$ (Fig. 9c). Within the same $500 \mathrm{~m} \times 500 \mathrm{~m}$ box centered on the updraft, wind speeds as low as $51 \mathrm{~m} \mathrm{~s}^{-1}$ are found, indicative of tremendous horizontal variability within the eyewall. At the location of the updraft maximum itself, the wind speed is approximately halfway between the nearby maximum and minimum.

Figure 10 shows $1 \mathrm{~km} \times 1 \mathrm{~km}$ horizontal cross sections (centered on the tracked feature) of vertical velocity (Figs. 10a,d), wind speed (Figs. 10b,e), and relative vertical vorticity (Figs. 10c,f), at the times of maximum wind speed and maximum vertical velocity (left and right panels, respectively). At the time of maximum wind speed, a $17 \mathrm{~m} \mathrm{~s}^{-1}$ circular updraft about $200 \mathrm{~m}$ in diameter is embedded within a broader region of weaker upward motion and is found at the downstream (northern) edge of an elongated region of very strong 

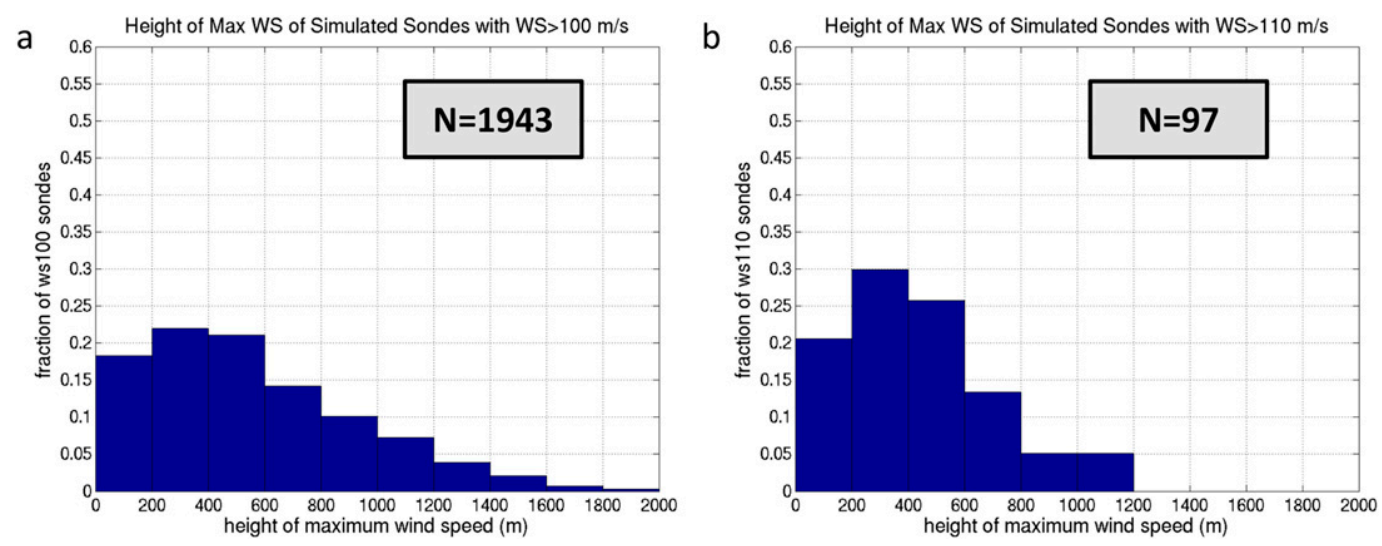

FIG. 8. As in Fig. 7, but for simulated sondes with wind speeds exceeding (a) 100 and (b) $110 \mathrm{~m} \mathrm{~s}^{-1}$. Note that here, a single PDF is computed using the full simulated sample, as there is no comparison to an observational sample.

vorticity with a peak near $0.45 \mathrm{~s}^{-1}$ and exceeding $0.3 \mathrm{~s}^{-1}$ at the location of the updraft. The wind speed maximum of $118 \mathrm{~m} \mathrm{~s}^{-1}$ is found just radially outward of the peak vorticity and outward and slightly azimuthally upstream of the updraft. Later $(t+81 \mathrm{~s})$, the updraft is larger (300$400 \mathrm{~m}$ in diameter), elongated azimuthally, and nearly tripled in strength to $45 \mathrm{~m} \mathrm{~s}^{-1}$. A $14 \mathrm{~m} \mathrm{~s}^{-1}$ downdraft has formed just upstream of the updraft. The vorticity maximum has strengthened to about $0.6 \mathrm{~s}^{-1}$ and is now nearly collocated with the updraft. Though the wind speed associated with the updraft at this height has decreased by nearly $20 \mathrm{~m} \mathrm{~s}^{-1}$, there are still local maxima of about $100 \mathrm{~m} \mathrm{~s}^{-1}$ along the outer edge of the updraft. Across the vorticity maximum, the wind speed varies by $42 \mathrm{~m} \mathrm{~s}^{-1}$ over about $100 \mathrm{~m}$. Just outward of the peak updraft, there is a local pressure minimum that is $\approx 10 \mathrm{mb}$ lower than its surroundings, collocated with a maximum in horizontal vorticity magnitude exceeding $1.0 \mathrm{~s}^{-1}$ (not shown). Although the dynamics of such features are complex, it is clear that this extreme updraft and wind gust are closely intertwined and associated with a coherent vortex. This is consistent with the observational studies of Aberson et al. (2006) and Marks et al. (2008) and supports the hypothesis of S16 that extreme updrafts and wind speeds sampled by dropsondes are likely related to such vortices.

Very recently, Wurman and Kosiba (2018) presented in situ and Doppler radar evidence of subkilometer tornado-scale vortices (TSVs) in the eyewall of Hurricane Harvey (2017) at landfall, and they were able to associate particular radar-detected TSVs with localized damage swaths. Wurman and Kosiba (2018) found that the TSVs were common within the eyewall of Harvey, had typical wind speed perturbations of $10-20 \mathrm{~m} \mathrm{~s}^{-1}$, and could be tracked for periods of $60-240 \mathrm{~s}$. All of these characteristics are consistent with the features seen in our simulation. One difference is that the peak observed 3 -s gust at $10 \mathrm{~m} \mathrm{AGL} \mathrm{in} \mathrm{Harvey} \mathrm{was} \mathrm{only} 62 \mathrm{~m} \mathrm{~s}^{-1}$, but this is consistent with the much weaker mean wind speed of $\approx 45 \mathrm{~m} \mathrm{~s}^{-1}$ (compared to $70-80 \mathrm{~m} \mathrm{~s}^{-1}$ in our simulation).

\section{Are the extreme updrafts and wind speeds rare?}

In S16, we concluded that it is likely that extreme updrafts and wind gusts are always present in intense hurricanes but that given their small size, it is challenging to sample these features. From the observations alone, it is difficult to determine if, for example, a sonde was "lucky" to have sampled a rare $100 \mathrm{~m} \mathrm{~s}^{-1}$ gust, or if instead there were many such gusts within the eyewall of such a storm. With the virtual sondes, we can try to answer this question.

\section{a. Strength of the peak simulated wind gusts and updrafts}

As discussed earlier, the peak simulated instantaneous wind gusts are typically $125-135 \mathrm{~m} \mathrm{~s}^{-1}$ and occasionally exceed $140 \mathrm{~m} \mathrm{~s}^{-1}$ (Fig. 1c). In comparison, the strongest wind speed measured by an observed dropsonde is $111.1 \mathrm{~m} \mathrm{~s}^{-1}$ in Supertyphoon Megi (2010) at about 150-m height (see Fig. 4b of S16). This is exceeded only by an in situ tower measurement of $113.3 \mathrm{~m} \mathrm{~s}^{-1}$ at 10-m height in Cyclone Olivia (1996) as it passed over Barrow Island, Australia (Courtney et al. 2012). We will show that this apparent discrepancy in the strength of the most extreme wind gusts is likely explained by observational undersampling.

Figure 11 shows the time series of the peak updrafts (Fig. 11a) and downdrafts (Fig. 11b) for the simulation. After a short adjustment period of about $10 \mathrm{~min}$, the peak vertical velocities reach a quasi-steady state, as with the peak wind gusts shown in Fig. 1. The strongest 

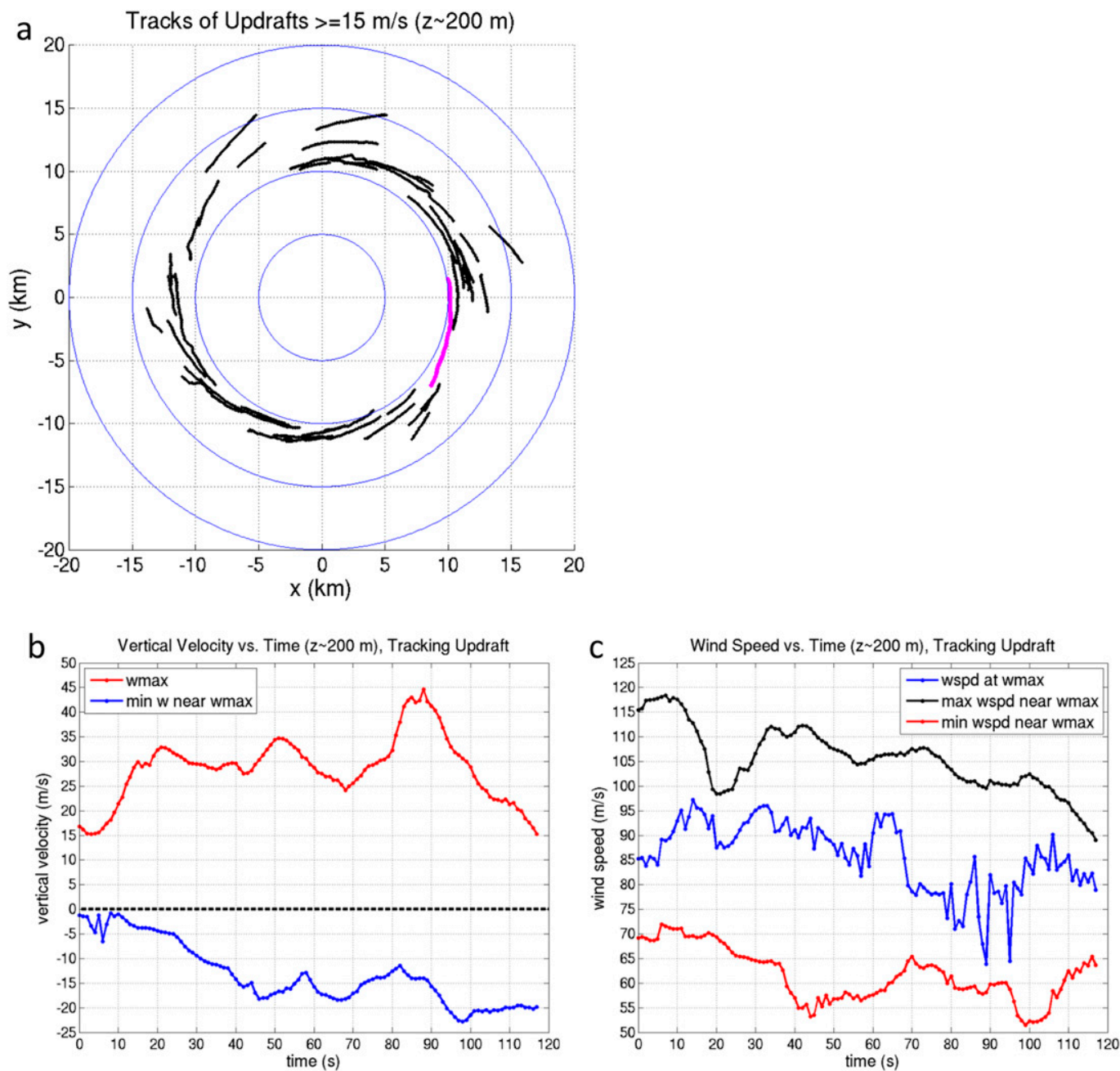

FIG. 9. (a) Horizontal tracks of updrafts exceeding $15 \mathrm{~m} \mathrm{~s}^{-1}$ at approximately $200-\mathrm{m}$ height. Range rings are shown every $5 \mathrm{~km}$. (b) Vertical velocity of the tracked updraft and the minimum vertical velocity within a $500 \mathrm{~m} \times$ $500 \mathrm{~m}$ box centered on the updraft. (c) Wind speed at the location of updraft, and maximum and minimum wind speed within a $500 \mathrm{~m} \times 500 \mathrm{~m}$ box centered on the updraft. The thick magenta trajectory in (a) is the updraft that becomes the strongest during this period, which is analyzed in (b) and (c) and in Fig. 10.

updrafts are generally between 35 and $45 \mathrm{~m} \mathrm{~s}^{-1}$, although there are occasional updrafts as strong as 50 $60 \mathrm{~m} \mathrm{~s}^{-1}$. The magnitudes of the strongest downdrafts are consistently about $70 \%-75 \%$ of those of the strongest updrafts (Fig. 11c), with typical peak downdrafts of $25-30 \mathrm{~m} \mathrm{~s}^{-1}$. For comparison, the strongest updraft in the dataset of S16 was $23.9 \mathrm{~m} \mathrm{~s}^{-1}$ in Hurricane Kenna (2002); this has since been exceeded by a $27.4 \mathrm{~m} \mathrm{~s}^{-1}$ updraft measured by a sonde in Hurricane Patricia (2015) (Rogers et al. 2017). An even stronger updraft of about $31 \mathrm{~m} \mathrm{~s}^{-1}$ was measured in situ by the $\mathrm{P} 3$ aircraft in Hurricane Felix (2007) (Aberson et al. 2017). Though S16 did not specifically search for sondes with extreme downdrafts, many of the w10 sondes also sampled strong downdrafts, with the strongest being $22.7 \mathrm{~m} \mathrm{~s}^{-1}$ in
Hurricane Ivan (2004). Aberson et al. (2017) found that a dropsonde released $4 \mathrm{~km}$ away from the extreme updraft encountered by the P3 in Felix sampled a $25 \mathrm{~m} \mathrm{~s}^{-1}$ downdraft just below where saturation first occurred. Interestingly, the strongest observed downdrafts are more comparable to the strongest simulated downdrafts, though this may be fortuitous. As with the extreme wind gusts, the discrepancy between the strongest simulated and observed low-level updrafts is likely explained by undersampling.

\section{$b$. Where are the strongest wind speeds found?}

Figure 12a shows the azimuthal-mean wind speed averaged over the final hour of the simulation, overlaid with the drop points and locations of wind speed maxima 

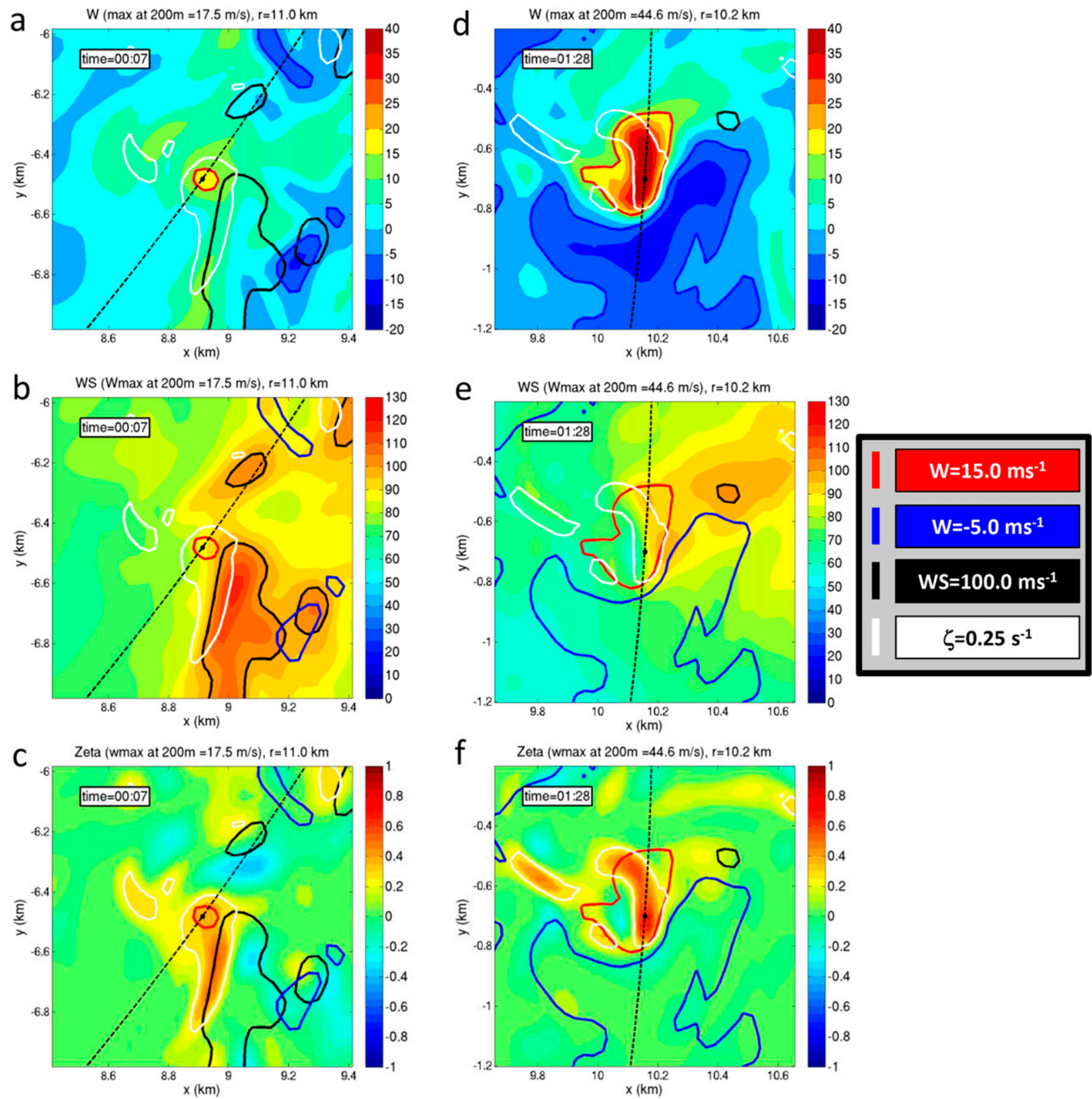

FIG. 10. For the tracked updraft shown in Fig. 9, horizontal cross sections of (a),(d) vertical velocity, (b),(e) wind speed, and (c),(f) relative vertical vorticity $\zeta$ at the time of (left) peak wind speed and (right) peak vertical velocity. Each panel shows a $1 \mathrm{~km} \times$ $1 \mathrm{~km}$ box centered on the updraft, and the black dashed line is a portion of a circle about the TC center, at the radius of the updraft. The location of peak vertical velocity (and center of each panel) is indicated by the black dot. Other contours are defined in the legend and are the same in all panels. The time elapsed (min:sec) since the beginning of tracking is indicated in each panel, and this corresponds to the time series in Figs. $9 \mathrm{~b}$ and $9 \mathrm{c}$.

for the 97 virtual sondes that sampled wind speeds greater than $110 \mathrm{~m} \mathrm{~s}^{-1}$ (in keeping with our convention, also termed "ws110" sondes). Almost all of the maxima exceeding $110 \mathrm{~m} \mathrm{~s}^{-1}$ occur within the region where the mean wind speed is greater than $80 \mathrm{~m} \mathrm{~s}^{-1}$, which is also within the mean eyewall updraft (as defined by $w \geq$
$1 \mathrm{~m} \mathrm{~s}^{-1}$ ). Consistent with Fig. $8 \mathrm{~b}$, most of the $110 \mathrm{~m} \mathrm{~s}^{-1}$ gusts are sampled below 500-m height, and all are below $1200 \mathrm{~m}$. Nearly all of the virtual sondes that sampled the $110 \mathrm{~m} \mathrm{~s}^{-1}$ gusts were dropped inward of the mean updraft and about 4-8 km inward of the "flight-level" RMW (approximately $18.5 \mathrm{~km}$ ). This is a consequence 



of the substantial outward slope of the low-level RMW, which is induced by surface friction (Kepert 2001; Kepert and Wang 2001). Even for intense hurricanes, the effect of the radial drift of dropsondes is relatively small (e.g., Kepert 2006a), and in our simulation, most ws110 sondes land within a 1 - or $2-\mathrm{km}$ radius of where they were dropped. On average, the peak sampled wind speed actually occurs about $750 \mathrm{~m}$ outward of the drop location, as the sondes spend most of their time within outflow. Therefore, the slope of the RMW has a much greater effect on the sampling of maximum winds than does the radial displacement of sondes as they fall, which is consistent with the discussion of Powell et al. (2009). To sample the strongest wind gusts, it is necessary to drop sondes nearly directly above the boundary layer tangential wind jet, which is about $5 \mathrm{~km}$ inward of the flight-level RMW for this simulation. This supports current operational practices and is consistent with observations of RMW slope (Powell et al. 2009). Note that S16 found that the median drop location of the observed ws 90 sondes was $4 \mathrm{~km}$ inward of the flight-level RMW, which is also consistent with this simulation.



FIG. 11. Over the entire domain of the LES, time series (every $15 \mathrm{~s}$ ) of (a) maximum vertical velocity, (b) minimum vertical velocity, and (c) the ratio of the magnitudes of minimum and maximum vertical velocity.

Also shown in Fig. 12a are the drop points and locations of updraft maxima for the 138 virtual sondes that sampled vertical velocities greater than $25 \mathrm{~m} \mathrm{~s}^{-1}$ ("w25" sondes). Note that five of the ws 110 sondes are also w25 sondes. Consistent with Fig. 7, the most extreme updrafts are found over a much deeper layer than the most extreme horizontal wind speeds, and this is also consistent with the observations of S16. Some of the w25 sondes exhibit peak vertical velocities well above the release height, and this is due to the upward movement of sondes within updrafts that exceed the sonde fall speed $\left(10-12 \mathrm{~m} \mathrm{~s}^{-1}\right)$. All of the peak updrafts occur within or very near to the mean eyewall updraft. The innermost drop radius of the w25 sondes is about the same as for the ws110 sondes, but there are more w25 sondes dropped farther outward, up to approximately the flight-level RMW. The reason for this difference is again that the extreme updrafts exist within a deeper layer, including at and above flight level, and since the eyewall slopes outward, the more elevated updrafts are sampled by sondes that are released farther outward. 



FIG. 12. (a) Azimuthal- and time-mean $(t=3-4 \mathrm{~h})$ wind speed. Time mean of the (b) maximum wind speed, (c) minimum wind speed, and (d) difference between the maximum and minimum wind speed. Azimuthal- and time-mean (e) simulated radar reflectivity and (f) relative humidity. For all panels except (e), the azimuthal-mean $1 \mathrm{~m} \mathrm{~s}^{-1}$ updraft is contoured in magenta. In (e), the $0.1 \mathrm{~g} \mathrm{~kg}^{-1} \mathrm{cloud}$ water mixing ratio is contoured in blue. In (d), the azimuthal-mean wind speed is contoured every $10 \mathrm{~m} \mathrm{~s}^{-1}$ in white. For all panels except (d), the release locations of the ws110 and w25 virtual sondes are indicated by white and black circles, respectively, and the respective locations of maximum wind speed and vertical velocity are indicated by white and black dots, respectively. 
Figures $12 \mathrm{~b}$ and $12 \mathrm{c}$ are similar to Fig. 12a, but instead of the azimuthal-mean wind speed, they respectively show the maximum and minimum wind speeds at each radius and height. As with the azimuthal-mean analysis, we average the maximum and minimum in time over the last hour of the simulation (in order to smooth the somewhat noisy snapshots), and so the peaks in the plots somewhat underestimate the true time mean of the extremes. For example, the mean of the maximum wind speed over the 61 snapshots is $124.9 \mathrm{~m} \mathrm{~s}^{-1}$, whereas the maximum shown in the 1 -h mean field is $112.8 \mathrm{~m} \mathrm{~s}^{-1}$. The former value is more representative of the actual typical peak wind speed within the simulation, but the timeaveraged field is qualitatively consistent and allows us to see where the simulated dropsondes are found relative to the location of the true peak wind speed. Perhaps not surprisingly, the dropsondes that sample $110 \mathrm{~m} \mathrm{~s}^{-1}$ gusts are mostly found where the time-mean maximum wind speed is near or exceeds $110 \mathrm{~m} \mathrm{~s}^{-1}$. Very few of these sonde-sampled maxima are found beyond the region where the time-mean maximum wind speed exceeds $100 \mathrm{~m} \mathrm{~s}^{-1}$. Together, this indicates that the most extreme wind gusts are not rare transient phenomena, but instead are ubiquitous features of the shallow and narrow region where azimuthal-mean wind speed is strongest. Further, it can be seen that the region of strongest wind gusts is nearly aligned with the axis of strongest azimuthal-mean wind speed. At the same radius-height location where the strongest wind gusts are found, there are also wind speeds as low as $60-65 \mathrm{~m} \mathrm{~s}^{-1}$ (Fig. 12c). As shown in Fig. 12d, average differences between the strongest and weakest winds at a given radius-height location are nearly $60 \mathrm{~m} \mathrm{~s}^{-1}$ in the lowest $100 \mathrm{~m}$ above the surface, in the region of strong radial gradient of the azimuthalmean wind speed. Even at the location of strongest azimuthal-mean wind speed, the average difference between the maximum and minimum wind speeds exceeds $45 \mathrm{~m} \mathrm{~s}^{-1}$, indicating a tremendous amount of variability within the mean boundary layer jet.

Figure 12e shows the azimuthal-mean simulated radar reflectivity, along with the $0.1 \mathrm{~g} \mathrm{~kg}^{-1}$ cloud water mixing ratio. The ws 110 virtual sondes are generally released in the region of strongest reflectivity gradient (i.e., across the inner edge of the eyewall). Some ws 110 sondes are released within the "flight-level" eye, and they fall into the sloping eyewall cloud. Just inward of the eyewall updraft, there is a sharp gradient in relative humidity (Fig. 12f), and many of the sondes that eventually sample the strongest wind speeds are released within the relatively dry $(\mathrm{RH}=70 \%-85 \%)$ region that would be generally considered to be the eye. These characteristics are consistent with the observations of extreme wind speeds in Hurricane Isabel (2003) presented by
S16 (their Figs. 16-18). Many of the w25 sondes are also released within either the eye or the eye/eyewall interface, although some are released closer to the highreflectivity eyewall core, consistent with the deeper layer of extreme updrafts as compared to extreme wind gusts.

For this simulation, the azimuthal-mean vertical velocity increases monotonically with height at low levels (Fig. 13a), with a maximum at 5-km height. Although the locations of peak wind gusts are well related to the location of peak azimuthal-mean wind speed (Fig. 12a), this is not the case for the relationship between the locations of peak updrafts and azimuthal-mean vertical velocity. As seen in Fig. 13b, there are two distinct maxima in time-averaged maximum updraft strength: one at about $4.8-\mathrm{km}$ height $\left(28.0 \mathrm{~m} \mathrm{~s}^{-1}\right)$ and another at

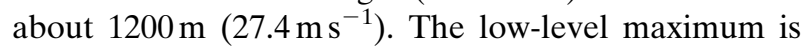
in a region where the azimuthal-mean updraft is less than half of that at the midlevel maximum, and many of the strongest sonde-sampled updrafts are found where the mean vertical velocity is relatively "weak." This difference between azimuthal-mean structure and distribution of extreme updrafts is related to the distribution of extreme downdrafts, which of course also contributes to the azimuthal mean. Figure $13 \mathrm{c}$ shows that on average, the strongest downdrafts are found within the lowest kilometer, and peak downdraft strength generally decreases monotonically above. In fact, there are very few downdrafts at all in the midlevel eyewall in this simulation, with nearly $100 \%$ positive vertical velocity for a narrrow corridor within the mean eyewall updraft above about $2.5-\mathrm{km}$ height (Fig. 13d). There are downdrafts that flank either side of the midlevel eyewall, though these are weaker than the downdrafts found within the boundary layer.

That the extreme updrafts are found over a deeper layer than are the extreme wind gusts (as seen in both the simulation and the observations) appears to reflect two factors. First, the peak azimuthal-mean wind speed is found much lower than the peak azimuthal-mean vertical velocity (cf. Figs. 12a and 13a), and the increase of the mean updraft with height in the lower troposphere allows for the strongest local updrafts to occur over a deep layer, even if the perturbations are smaller at greater heights. Second, the region of strongest vertical velocity perturbations is relatively deep (nearly constant over the lowest $2 \mathrm{~km}$; Fig. 13f), whereas the strongest wind speed perturbations are found near the surface and rapidly decrease in magnitude with height (Fig. 12d). The low-level peak of the mean wind speed is understood to result from the supergradient boundary layer jet (Kepert and Wang 2001; Kepert 2006b), and the midlevel peak of the mean updraft is likely related to 

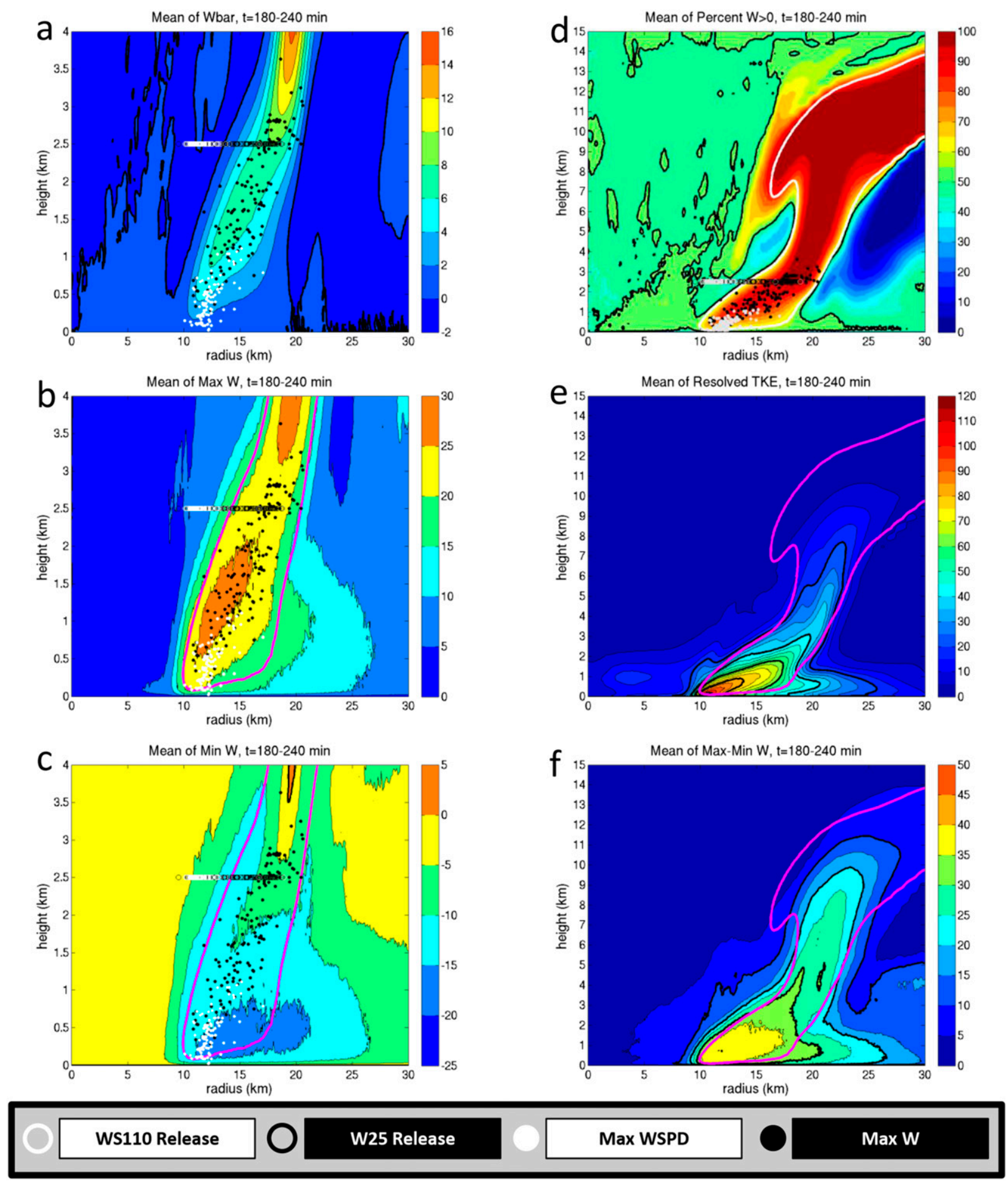

FIG. 13. (a) Azimuthal- and time-mean $(t=3-4 \mathrm{~h})$ vertical velocity. Time mean of the (b) maximum and (c) minimum vertical velocity, and (d) percentage of grid points with $w>0 \mathrm{~m} \mathrm{~s}^{-1}$. (e) Azimuthal and time mean of the resolved TKE. (f) Time mean of the difference between the maximum and minimum vertical velocity. The $1 \mathrm{~m} \mathrm{~s}^{-1}$ azimuthal-mean updraft is contoured in magenta for (b),(c),(e),(f) and in white for (d). The $50 \%$ contour is in black in (d). For (a)-(d), the release locations of the ws 110 and w 25 virtual sondes are indicated by white and black circles, respectively, and the respective locations of maximum wind speed and vertical velocity are indicated by white and black dots, respectively. Note that (a)-(c) show only the lowest $4 \mathrm{~km}$ (as in Fig. 12), whereas (d)-(f) extend to $z=15 \mathrm{~km}$. 
the integrated effects of buoyancy. The reason for the differences in the vertical structure of the perturbation wind speed and vertical velocity is currently unclear. We speculate that local buoyancy becomes important for the more elevated extreme updrafts, which results in large perturbation vertical velocities in the absence of similarly large perturbation wind speeds.

\section{c. What is the likelihood of sampling the strongest wind speeds and updrafts with dropsondes?}

The typical peak instantaneous wind speed in our simulation of $\approx 130 \mathrm{~m} \mathrm{~s}^{-1}$ exceeds (by about $15 \%$ ) the strongest gust ever observed in a tropical cyclone. Further, although 14 different storms of category 5 intensity have been sampled by GPS dropsondes through 2016, there are only eight dropsondes that have ever measured wind speed in excess of $100 \mathrm{~m} \mathrm{~s}^{-1}$, and six of those were from Supertyphoon Megi, with one each from Hurricanes Isabel (2003) and Ivan (2004). From a subjective count, there have been roughly 300 dropsondes released within the eyewalls of observed category 5 hurricanes, though the number per storm varies greatly, and nearly half of such sondes were released in a single storm (Isabel). Hurricane Patricia, which by some estimates is the strongest TC ever observed, had a peak dropsondemeasured wind speed of only $98.3 \mathrm{~m} \mathrm{~s}^{-1}$ (Rogers et al. 2017)..$^{5}$ As all but one ${ }^{6}$ observed category 5 TC has had at least one sonde-measured wind speed exceeding $90 \mathrm{~m} \mathrm{~s}^{-1}$, we can infer that gusts of this magnitude are quite common within such storms. From the observations alone, it is unclear if gusts of $100-110 \mathrm{~m} \mathrm{~s}^{-1}$ are typical or not for intense TCs. It is also unclear how realistic the simulated wind gusts of $120-140 \mathrm{~m} \mathrm{~s}^{-1}$ are, given that we have never observed such wind speeds in tropical cyclones. We can address both these questions with the simulated dropsondes.

Figure 14 shows the percentage of simulated dropsondes that sample instantaneous wind speeds exceeding thresholds varying from 90 to $110 \mathrm{~m} \mathrm{~s}^{-1}$, binned by drop radius every kilometer. Consistent with Fig. 12, the highest frequency of sampling extreme wind speeds

\footnotetext{
${ }^{5}$ The NOAA dropsonde that sampled the peak wind speed failed at $1100 \mathrm{~m}$, and there were only four eyewall sondes with data in the lowest kilometer from that flight. There are no available AVAPS files from the earlier AF flight, but the TEMPDROP messages indicate a sonde that sampled a $99 \mathrm{~m} \mathrm{~s}^{-1}$ wind speed. Additionally, 1-s flight-level winds of 103 and $105 \mathrm{~m} \mathrm{~s}^{-1}$ were measured on the AF and NOAA missions, respectively.

${ }^{6}$ The peak sonde-measured wind in Hurricane Matthew (2016) was only $78 \mathrm{~m} \mathrm{~s}^{-1}$, but this is likely explained by the fact that there were only three sondes that measured low-level winds within the eyewall when Matthew was a category 5 storm, and these sondes all likely missed the band of strongest winds.
}

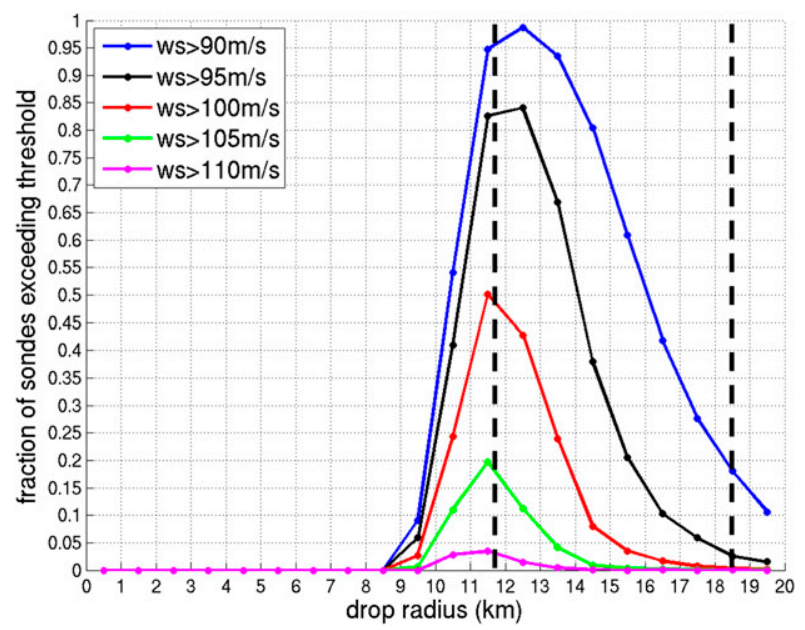

FIG. 14. Fraction of virtual sondes that sample (instantaneous) wind speeds exceeding thresholds of 90, 95, 100, 105, and $110 \mathrm{~m} \mathrm{~s}^{-1}$. Sondes are binned in 1-km intervals, and plotting is at the center of each bin. The vertical dashed black lines indicate the RMW at the (outer line) release height and (inner line) surface.

occurs for sondes dropped between about 4 and $8 \mathrm{~km}$ inward of the "flight-level" RMW. A random sonde dropped in this region is very likely to sample a $90 \mathrm{~m} \mathrm{~s}^{-1}$ wind gust, qualitatively consistent with observations of category 5 TCs. As the threshold increases, however, the probability of sampling such gusts becomes rather low. In total, $50 \%$ of sondes dropped between radii of 11 and $12 \mathrm{~km}$ sample gusts exceeding $100 \mathrm{~m} \mathrm{~s}^{-1}$. This may seem high compared to observations, but the probabilities drop off sharply on either side of this narrow peak, and for a real storm, it is unknown precisely which radius will maximize the sampled winds, so a single eyewall sonde is still unlikely to sample such a gust. The observed ws 90 sondes were mostly dropped over a $10-\mathrm{km}$ radial range relative to the flight-level RMW (see Fig. 6c of S16), indicating that a typical eyewall sonde will often miss sampling a 1-km-wide region of peak gusts. The peak probability of sampling a gust exceeding $110 \mathrm{~m} \mathrm{~s}^{-1}$ within the simulation is less than $5 \%$, and this is qualitatively consistent with the fact that only one such gust has been observed by dropsondes. Out of 15056 simulated sondes dropped between $10-$ and $20-\mathrm{km}$ radius, there is but a single sonde that sampled a gust exceeding $120 \mathrm{~m} \mathrm{~s}^{-1}\left(120.7 \mathrm{~m} \mathrm{~s}^{-1}\right.$; not shown). This is in spite of the fact that there are nearly always gusts exceeding $125 \mathrm{~m} \mathrm{~s}^{-1}$ somewhere within this simulated hurricane. It is extremely unlikely that a virtual sonde dropped within the eyewall of the simulated storm will sample gusts exceeding about $110 \mathrm{~m} \mathrm{~s}^{-1}$, which is similar to the strongest observed gust. Given these results, it is reasonable to suppose that real category 5 hurricanes 

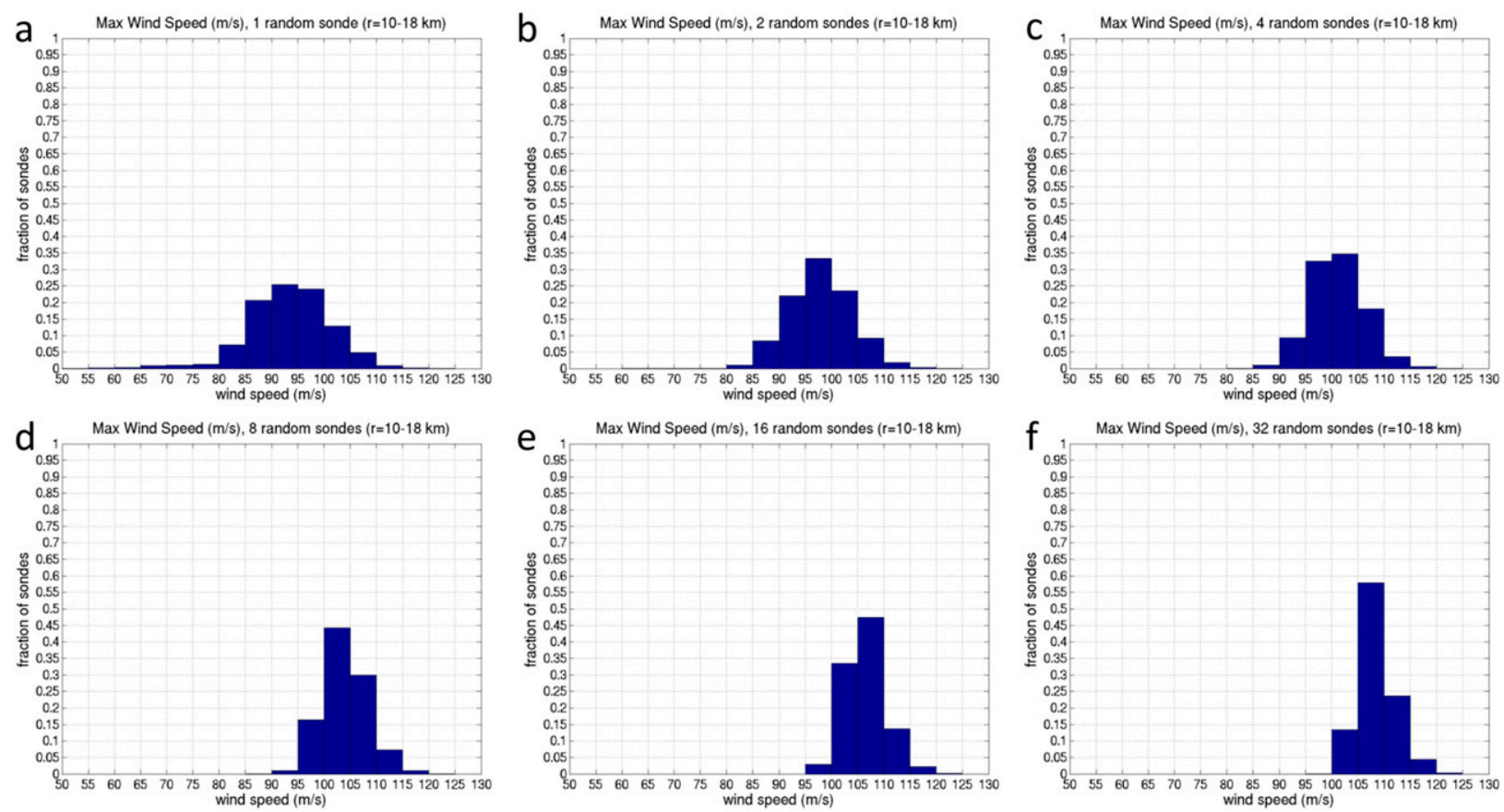

FIG. 15. PDFs of the maximum wind speed sampled by combinations of (a) 1, (b) 2, (c) 4, (d) 8, (e) 16, or (f) 32 random virtual sondes released within the eyewall $(r=10-18 \mathrm{~km})$. Details are described in the text.

contain peak gusts of $120-140 \mathrm{~m} \mathrm{~s}^{-1}$ that have never been observed.

We can also estimate the probability that a given flight through a category 5 hurricane will sample (with dropsondes) extreme wind gusts of various thresholds. Figure 15 shows the probability distribution of peak wind speed sampled by random combinations of dropsondes released between $10-$ and $18-\mathrm{km}$ radius. For this analysis, we assume that a hypothetical aircraft would release sondes in this region with a uniform probability in radius, and so for each sonde, we first randomly choose one of eight 1-km-wide radial bins and then randomly choose a sonde from within the chosen bin. This is done for combinations of $1,2,4,8,16$, and 32 sondes, and for each set of sondes, we find the maximum wind speed over the set. For each of these six sonde combinations, we repeat this procedure 10000 times, resulting in six different PDFs of peak sampled wind speed.

For a single random sonde dropped in the eyewall, the peak sampled wind speed is most likely to be 90 $95 \mathrm{~m} \mathrm{~s}^{-1}$, though the spread is relatively large, and there is also substantial probability of the peak being $85-90$ or $95-100 \mathrm{~m} \mathrm{~s}^{-1}$. This single-sonde scenario is perhaps the most representative. Although most observational missions drop at least four eyewall sondes, there is a strong preference for the peak wind speed to be found in one half or one quadrant of the storm (S16). Our simulation has no such preference because there is no vertical wind shear or storm motion, but in a real TC, at least half of the eyewall sondes are unlikely to be in a favorable region to sample the maximum winds. This likely in part explains why the probabilities of sampling wind gusts exceeding $90 \mathrm{~m} \mathrm{~s}^{-1}$ are somewhat higher here as compared to observations (Fig. 6d), along with the fact that the simulated storm is somewhat more intense than the average of the observed storms. As we increase the number of sondes, the most likely peak sampled wind speed increases, and the PDF also narrows. With eight random sondes, there is a $45 \%$ chance of the peak falling between 100 and $105 \mathrm{~m} \mathrm{~s}^{-1}$. Even with 32 sondes, there is a $70 \%$ chance that the peak sampled wind speed is less than $110 \mathrm{~m} \mathrm{~s}^{-1}$. Therefore, even with dropsonde coverage much greater than is typical, it is likely that the peak wind gusts will be greatly underestimated by 15 $30 \mathrm{~m} \mathrm{~s}^{-1}$.

It is worthwhile to compare the above results to the recent studies of Uhlhorn and Nolan (2012) and Nolan et al. (2014), which highlighted the consequences of undersampling in the estimation of tropical cyclone intensity (as defined by the maximum 1-min wind speed at $10 \mathrm{~m}$ ASL). For a high-resolution $(\Delta x=1.33 \mathrm{~km})$ simulation of Hurricane Isabel (2003), Uhlhorn and Nolan (2012) found using simulated SFMR observations that a typical flight pattern underestimated the true intensity $\left(60-70 \mathrm{~m} \mathrm{~s}^{-1}\right)$ by, on average, $5.5 \mathrm{~m} \mathrm{~s}^{-1}(8.5 \%)$. 
Nolan et al. (2014) analyzed simulated anemometer data for a "nature run" simulation (Nolan et al. 2013) and found that a random, but ideally located (near the RMW and on the right side of the TC), anemometer underestimated the true intensity $\left(66 \mathrm{~m} \mathrm{~s}^{-1}\right)$ by, on average, $9 \mathrm{~m} \mathrm{~s}^{-1}(12 \%)$. Our present study examines peak instantaneous wind gusts at any height (not just $10 \mathrm{~m}$ ), and so our simulated dropsonde analyses are not directly comparable to Uhlhorn and Nolan (2012) and Nolan et al. (2014). Nevertheless, it is clear that undersampling by dropsondes is more severe than either SFMR or fixed anemometers, as a single dropsonde in our simulation will typically underestimate the true peak instantaneous gust $\left(\approx 130 \mathrm{~m} \mathrm{~s}^{-1}\right)$ by $30-40 \mathrm{~m} \mathrm{~s}^{-1}$ $(\approx 20 \%-30 \%)$. We also examined the maximum 1-min surface wind speed in our simulation using simulated anemometers (not shown) and found that the true intensity was underestimated by, on average, $6 \%$, comparable to (though somewhat less than) the results of Nolan et al. (2014). In a future study, we plan to more directly assess the underestimation of TC intensity itself by dropsondes.

\section{How strong are the strongest wind gusts in tropical cyclones?}

For measuring maximum short-period gusts, there is currently no substitute for dropsondes, except for the rare storm that happens to pass over an instrumented tower. There are two notable such cases: Cyclone Olivia (1996) and Cyclone Orson (1989), both of which passed over towers off the northwest coast of Australia. Olivia holds the current official world record for 3-s wind gust at $10 \mathrm{~m}$ AGL, measured as $113.3 \mathrm{~m} \mathrm{~s}^{-1}$ on Barrow Island, $6 \mathrm{~km}$ inland and $64 \mathrm{~m}$ ASL, as well as $50 \mathrm{~km}$ offshore of the mainland. Black et al. (1999) and Courtney et al. (2012) present a thorough discussion of this record wind gust and show that it occurred as the inner edge of the western eyewall passed over the station. Remarkably, the 5-min mean wind speed during the period of the peak gust was only $41.3 \mathrm{~m} \mathrm{~s}^{-1}$, and indeed, the official intensity of Olivia corresponded to a maximum 1-min mean wind speed of only $115 \mathrm{kt}$. Although it is likely that the peak wind gusts were somewhat enhanced beyond what they would be over the open ocean, this still indicates that the true peak wind gusts in stronger storms must be substantially higher than what was observed in Olivia, and this inference is consistent with what we find in our simulation.

Cyclone Orson passed over an offshore $(130 \mathrm{~km}$ from the mainland) natural gas production platform as a category $5 \mathrm{TC}$ with an official peak 1-min wind speed of $140 \mathrm{kt}$. An anemometer at $36.4 \mathrm{~m}$ ASL measured a peak 1-min wind speed of $66.4 \mathrm{~m} \mathrm{~s}^{-1}$ and a peak 3-s wind speed of $132.6 \mathrm{~m} \mathrm{~s}^{-1}$, which, if valid, would be by far the strongest wind gust ever directly measured (Harper et al. 2010). As discussed by Harper et al. (2010), this measurement was originally dismissed as likely to be erroneous. However, Harper et al. (2010) note that the continuous time series of the 1-min mean wind speed appears to be reasonable, suggesting that the extreme 3 -s gust might actually be real. Ultimately, they conclude that the validity of this measurement cannot be determined, as the instrument was eventually destroyed, and so this measurement is not currently recognized as a record. Our analysis supports the conclusion that gusts of $130 \mathrm{~m} \mathrm{~s}^{-1}$ are indeed plausible for a category $5 \mathrm{TC}$.

Although gusts exceeding $110 \mathrm{~m} \mathrm{~s}^{-1}$ are very unlikely to be sampled with a random dropsonde, the probability of sampling such extremes is much higher for a given tower as compared to a given dropsonde. To illustrate this, we compare simulated tower data to simulated dropsonde data in Fig. 16. As described by Worsnop et al. (2017b), the towers (spaced at 1-km intervals) record $10 \mathrm{~min}$ of data at every time step and every model level below $500 \mathrm{~m}$ ASL. Figure 16a shows the peak instantaneous wind speed from the towers over this 10-min period, as a function of radius (binned each kilometer) and height (lowest $200 \mathrm{~m}$ is shown). Figure $16 \mathrm{~b}$ is similar, but shows the azimuthal mean (over all towers in each radial bin) of the peak instantaneous wind speed; in other words, this shows the expected value of the peak wind speed from a random tower at a given radius. Figures $16 \mathrm{e}$ and $16 \mathrm{f}$ are analogous to Figs. 16a and $16 \mathrm{~b}$, but instead are for the simulated dropsondes, binned every $1 \mathrm{~km}$ by the drop radius and vertically every $20 \mathrm{~m}$. Despite having 16 times the horizontal density of the towers, the simulated dropsondes sample peak wind speeds that are $20 \mathrm{~m} \mathrm{~s}^{-1}$ less than sampled by the simulated towers (cf. Figs. 16a,e), with the expected value for a random dropsonde weaker by nearly $25 \mathrm{~m} \mathrm{~s}^{-1}$ (cf. Figs. 16b,f). This difference is because a fixed tower samples the same location for a much longer period of time than does a dropsonde. From a practical standpoint, observed TCs tend to have the strongest winds sampled by dropsondes and not towers, simply because very few storms have any tower data at all. From the perspective of risk, however, simulated towers are much more representative of the fixed structures that are in the path of TCs and that are susceptible to damage or destruction. Therefore, the risk to structures from extreme wind gusts is substantially greater than that implied by the dropsonde observations.

Finally, in order to more directly compare our simulation to the observations of Cyclones Olivia and Orson, Figs. 16c and 16d are the same as Figs. 16a and 16b, but 

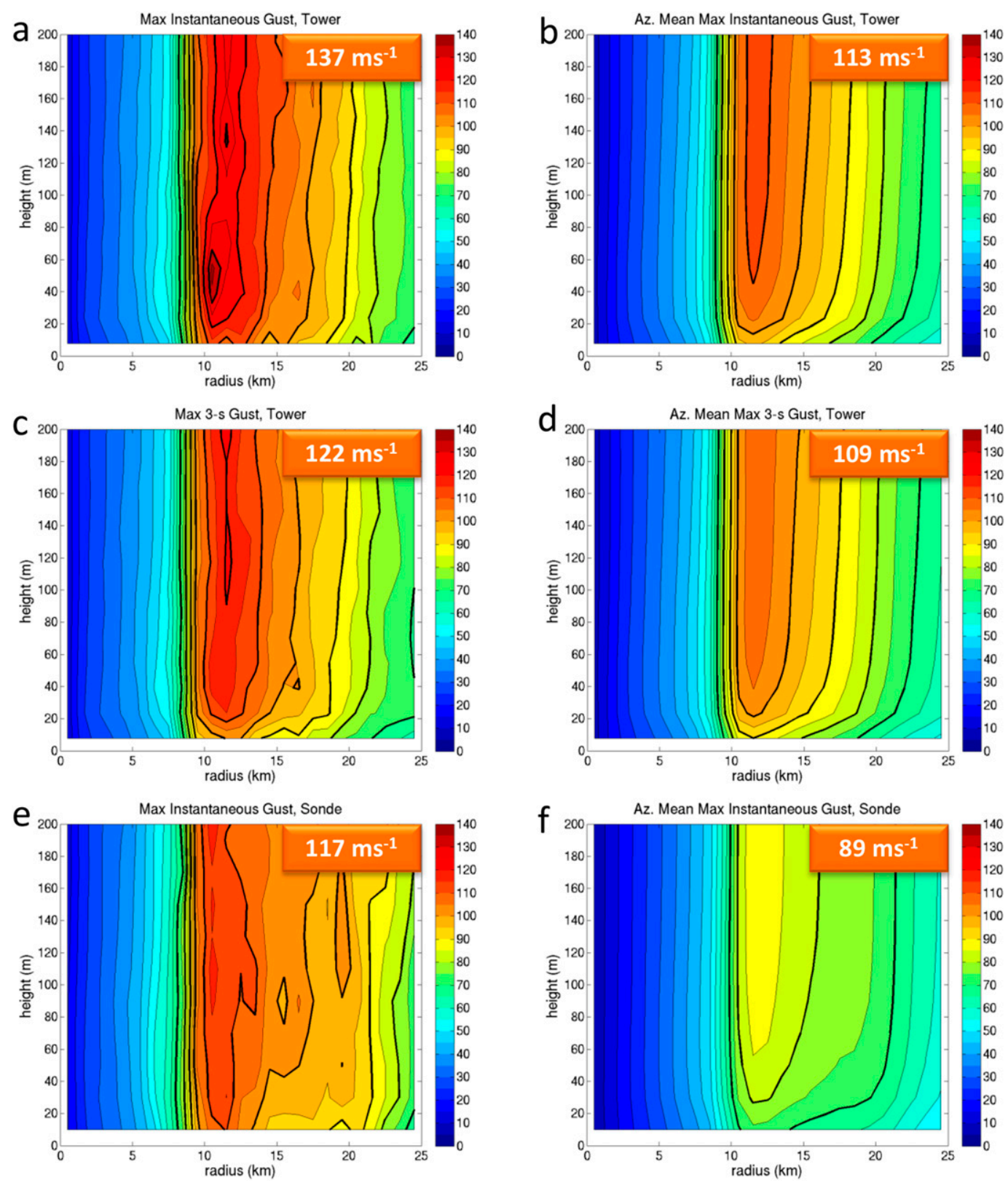

FIG. 16. Radius-height distributions of the peak gusts sampled by simulated (a)-(d) towers and (e),(f) dropsondes. (left) Maximum over all towers/sondes in each 1-km radial bin; (right) azimuthal mean of the maximum from the towers/ sondes in each bin. The peak instantaneous and 3-s gusts within a 10-min period are shown in the top and middle rows, respectively. The respective maximum values are indicated in each panel.

showing the peak 3-s gusts. The absolute maximum over all towers is $15 \mathrm{~m} \mathrm{~s}^{-1}$ weaker for the 3 -s gust as compared to the instantaneous wind speed (consistent with the time series of 10-m wind speed in Fig. 2a). However, on average, the 3-s gusts from any random tower are only a few meters per second less than the peak instantaneous wind speeds (cf. Figs. 16d,b). At the model level (39 m ASL) closest to the height of the Orson observations, the peak 3-s gust within a 10-min period from any tower is $119.2 \mathrm{~m} \mathrm{~s}^{-1}$, while the bin-averaged peak 3-s gust is $105.2 \mathrm{~m} \mathrm{~s}^{-1}$. For a real storm, the expected value of the peak gust will depend on the storm translation speed and the width of the eyewall, but the 10-min period of simulated data here appears comparable to the period of intense winds experienced by the tower in Orson [see Fig. 3.2a in Harper et al. (2010)]. Although it is possible that the Orson observation is either in error or is "lucky," this comparison may indicate that our simulation actually 
underestimates the strength of near-surface wind gusts. The validity of the Olivia surface observation is not in question, but the occurrence over slightly elevated terrain and over land makes a comparison to the simulation more uncertain. Nevertheless, the peak and bin-averaged 3-s wind gusts at $10 \mathrm{~m}$ from the simulated towers are 101.9 and $91.1 \mathrm{~ms}^{-1}$, respectively, substantially less than the $113.3 \mathrm{~m} \mathrm{~s}^{-1}$ observed in Olivia. Considering that the mean intensity of Olivia is actually estimated to be weaker than that of our simulation, this is again consistent with the simulation underestimating the near-surface wind gusts.

\section{Summary and conclusions}

In this study, we examined virtual dropsondes within a large-eddy simulation $(\Delta x=31.25 \mathrm{~m})$ of an intense hurricane to examine extreme low-level wind gusts and updrafts. These features were investigated with observed dropsondes in S16, where we found evidence that suggested that such extreme wind speeds and vertical velocities are associated with subkilometer-scale vortices that can exist along the eye/eyewall interface. In this current study, we aimed to 1) validate the ability of the LES to realistically simulate turbulence in an intense hurricane, 2) explore the nature of the features that produce extreme wind speeds, 3 ) determine the magnitude of the strongest gusts that are likely to occur within tropical cyclones, and 4) estimate the likelihood of sampling extreme wind speeds.

Starting from an axisymmetric vortex, our simulated TC developed statistically steady 3D turbulence within 10-20 min, with maximum 1-min surface winds $\left(80 \mathrm{~m} \mathrm{~s}^{-1}\right)$ representative of a strong category 5 hurricane. As in the observational dataset of S16, many of the simulated dropsondes sampled extreme wind gusts and/or updrafts, and it is fairly easy to find simulated sondes that exhibit wind speeds or vertical velocities that resemble observed sondes both in magnitude and in structure. Indeed, we showed that it is quite challenging to identify a real dropsonde from among a set of similar virtual sondes. This indicates that turbulent structures within the low-level eyewall are being reasonably well simulated in our LES.

S16 examined a dataset of all observed dropsondes that sampled wind speeds exceeding $90 \mathrm{~ms}^{-1}$ and/or updrafts exceeding $10 \mathrm{~ms}^{-1}$. Here, we compared the virtual to the observed dropsondes in terms of the distributions of the magnitudes of these extremes and the heights at which they were found. We found that qualitatively, the PDFs compared reasonably well, especially given that we were comparing a single simulation to a set of observations from many storms of varying intensities and sizes. Importantly, the most extreme sampled wind speeds and vertical velocities are similar between the virtual and observed dropsondes. In both observations and the simulation, the most extreme wind gusts are confined to a substantially shallower layer than that of the most extreme updrafts. Extreme wind gusts and updrafts can be found within the lowest 100-200 m above the surface in both observations and the simulation.

We presented an example of a particularly extreme simulated feature, characterized by peak instantaneous wind speeds and vertical velocities at 200-m height of 118 and $45 \mathrm{~ms}^{-1}$, respectively. We were able to track this feature in time for about $2 \mathrm{~min}$ as it moved tangentially and radially (inward) at about 75 and $10 \mathrm{~m} \mathrm{~s}^{-1}$, respectively, evidently steered by the mean TC circulation. This feature evolved quite rapidly, with the vertical velocity increasing by about $20 \mathrm{~m} \mathrm{~s}^{-1}$ over a period of only 20 s. Consistent with the hypothesis of S16 and with the observations of Aberson et al. (2006) and Marks et al. (2008), this extreme wind gust and updraft were both associated with a coherent vortex found along the inner edge of the eyewall. The spatial relationships among the wind speed, vertical velocity, and vertical vorticity appear to remain generally consistent in time: an updraft nearly collocated with a vorticity maximum, with a downdraft just azimuthally upstream and a wind speed maximum just radially outward and slightly upstream.

In our simulation, the strongest wind gusts and updrafts are found nearly exclusively within a narrow (approximately 5-km wide) zone encompassed by the sloping mean eyewall updraft, and this is consistent with the observational findings of S16. To sample the strongest wind gusts in the simulation, it is necessary to release the sondes $4-8 \mathrm{~km}$ inward of the "flight-level" RMW, and this is consistent with S16 and with existing operational practice for hurricane reconnaisance. There is tremendous variability of the local wind speed within the low-level eyewall, with a typical range of $40-50 \mathrm{~m} \mathrm{~s}^{-1}$ at the location of peak azimuthal-mean wind speed. As a result, any given dropsonde could happen to sample wind speeds much lower or higher than the mean.

Wind speeds within the simulation exceed $120 \mathrm{~m} \mathrm{~s}^{-1}$ somewhere within the TC at nearly all times, and occasionally there are wind speeds exceeding $150 \mathrm{~m} \mathrm{~s}^{-1}$. Such winds are substantially stronger than have ever been observed in TCs. Because of the small area encompassed by the most extreme winds, it seems unlikely that they would be sampled with dropsondes using presentday techniques, and we found that while wind speeds of $90-100 \mathrm{~m} \mathrm{~s}^{-1}$ are sampled fairly often by the simulated dropsondes, sampled winds exceeding about $110 \mathrm{~m} \mathrm{~s}^{-1}$ were extremely rare. This is consistent with the fact that wind speeds exceeding $90 \mathrm{~m} \mathrm{~s}^{-1}$ have been found in 
nearly all observed category 5 storms, but only one observed sonde has sampled greater than $110 \mathrm{~m} \mathrm{~s}^{-1}$. Of course, it is possible that there are biases in the simulation analyzed in this study, which may affect our results. Such potential biases could result from uncertainty in the surface stress and the subgrid-scale turbulence model, as well as from physical processes that are not explicitly included in the LES, including ocean waves. Nevertheless, the good agreement between the simulated and observed dropsondes leads us to conclude that it seems likely that $120-140 \mathrm{~m} \mathrm{~s}^{-1}$ instantaneous wind speeds are present in actual intense TCs.

Acknowledgments. Part of this research was performed at NCAR while the first author was an NSFAGS Postdoctoral Fellow (Award 1231193). D. Stern is supported by ONR through Program Element 0601153N. The National Center for Atmospheric Research is sponsored by the National Science Foundation. We would like to acknowledge high-performance computing support from Yellowstone (ark:/85065/d7wd3xhc) provided by NCAR's Computational and Information Systems Laboratory, sponsored by the National Science Foundation. The authors appreciate the helpful comments provided by Chris Davis on an earlier version of this manuscript, as well as the reviews provided by Jeff Kepert and two anonymous reviewers.

\section{REFERENCES}

Aberson, S. D., M. T. Montgomery, M. Bell, and M. Black, 2006: Hurricane Isabel (2003): New insights into the physics of intense storms. Part II: Extreme localized wind. Bull. Amer. Meteor. Soc., 87, 1349-1354, https://doi.org/10.1175/BAMS87-10-1349.

_ J. A. Zhang, and K. N. Ocasio, 2017: An extreme event in the eyewall of Hurricane Felix on 2 September 2007. Mon. Wea. Rev., 145, 2083-2092, https://doi.org/10.1175/MWR-D-16-0364.1.

Black, P. G., S. J. Buchan, and R. L. Cohen, 1999: The tropical cyclone eyewall mesovortex: A physical mechanism explaining extreme peak gust occurrence in TC Olivia, 4 April 1996 on Barrow Island, Australia. Proc. 31st Offshore Technology Conf., Houston, TX, OTC, OTC-10792-MS, https://doi.org/ 10.4043/10792-MS.

Bryan, G. H., 2012: Effects of surface exchange coefficients and turbulence length scales on the intensity and structure of numerically simulated hurricanes. Mon. Wea. Rev., 140, 11251143, https://doi.org/10.1175/MWR-D-11-00231.1.

—_, and J. M. Fritsch, 2002: A benchmark simulation for moist nonhydrostatic numerical models. Mon. Wea. Rev., 130, 2917-2928, https://doi.org/10.1175/1520-0493(2002) $130<2917$ :ABSFMN $>2.0 . \mathrm{CO} ; 2$.

— , and R. Rotunno, 2009: The maximum intensity of tropical cyclones in axisymmetric numerical model simulations. Mon. Wea. Rev., 137, 1770-1789, https://doi.org/10.1175/2008MWR2709.1.

_ , and H. Morrison, 2012: Sensitivity of a simulated squall line to horizontal resolution and parameterization of microphysics.
Mon. Wea. Rev., 140, 202-225, https://doi.org/10.1175/MWRD-11-00046.1.

— N. A. Dahl, D. S. Nolan, and R. Rotunno, 2017a: An eddy injection method for large-eddy simulations of tornado-like vortices. Mon. Wea. Rev., 145, 1937-1961, https://doi.org/ 10.1175/MWR-D-16-0339.1.

— , R. P. Worsnop, J. K. Lundquist, and J. A. Zhang, 2017b: A simple method for simulating wind profiles in the boundary layer of tropical cyclones. Bound.-Layer Meteor., 162, 475502, https://doi.org/10.1007/s10546-016-0207-0.

Computational and Information Systems Laboratory, 2016: Yellowstone: IBM iDataPlex/FDR-IB. NCAR-UCAR, http:// n2t.net/ark:/85065/d7wd3xhc.

Courtney, J., and Coauthors, 2012: Documentation and verification of the world extreme wind gust record: $113.3 \mathrm{~m} \mathrm{~s}^{-1}$ on Barrow Island, Australia, during passage of Tropical Cyclone Olivia. Aust. Meteor. Oceanogr. J., 62, 1-9, https://doi.org/10.22499/ 2.6201.001.

Dahl, N. A., D. S. Nolan, G. H. Bryan, and R. Rotunno, 2017: Using high-resolution simulations to quantify underestimates of tornado intensity from in situ observations. Mon. Wea. Rev., 145, 1963-1982, https://doi.org/10.1175/MWR-D-16-0346.1.

Deardorff, J. W., 1980: Stratocumulus-capped mixed layer derived from a three-dimensional model. Bound.-Layer Meteor., 18, 495-527, https://doi.org/10.1007/BF00119502.

Drennan, W. M., J. A. Zhang, J. R. French, C. McCormick, and P. G. Black, 2007: Turbulent fluxes in the hurricane boundary layer. Part II: Latent heat flux. J. Atmos. Sci., 64, 1103-1115, https://doi.org/10.1175/JAS3889.1.

Dunion, J. P., 2011: Rewriting the climatology of the tropical North Atlantic and Caribbean Sea atmosphere. J. Climate, 24, 893 908, https://doi.org/10.1175/2010JCLI3496.1.

Fierro, A. O., R. F. Rogers, F. D. Marks, and D. S. Nolan, 2009: The impact of horizontal grid spacing on the microphysical and kinematic structures of strong tropical cyclones simulated with the WRF-ARW Model. Mon. Wea. Rev., 137, 3717-3743, https://doi.org/10.1175/2009MWR2946.1.

Franklin, J. L., M. L. Black, and K. Valde, 2003: GPS dropwindsonde wind profiles in hurricanes and their operational implications. Wea. Forecasting, 18, 32-44, https://doi.org/10.1175/ 1520-0434(2003)018<0032:GDWPIH>2.0.CO;2.

Harper, B. A., J. D. Kepert, and J. D. Ginger, 2010: Guidelines for converting between various wind averaging periods in tropical cyclone conditions. WMO Tech. Rep. WMO-TD-1555, 64 pp., https://www.wmo.int/pages/prog/www/tcp/documents/WMO_ TD_1555_en.pdf.

Hock, T. F., and J. L. Franklin, 1999: The NCAR GPS dropwindsonde. Bull. Amer. Meteor. Soc., 80, 407-420, https://doi.org/ 10.1175/1520-0477(1999)080<0407:TNGD>2.0.CO;2.

Jeong, D., B. K. Haus, and M. A. Donelan, 2012: Enthalpy transfer across the air-water interface in high winds including spray. J. Atmos. Sci., 69, 2733-2748, https://doi.org/ 10.1175/JAS-D-11-0260.1.

Kepert, J. D., 2001: The dynamics of boundary layer jets within the tropical cyclone core. Part I: Linear theory. J. Atmos. Sci., 58, 2469-2484, https://doi.org/10.1175/1520-0469(2001)058<2469: TDOBLJ $>2.0 . \mathrm{CO} ; 2$. , 2006a: Observed boundary layer wind structure and balance in the hurricane core. Part I: Hurricane Georges. J. Atmos. Sci., 63, 2169-2193, https://doi.org/10.1175/JAS3745.1.

_ 2006b: Observed boundary layer wind structure and balance in the hurricane core. Part II: Hurricane Mitch. J. Atmos. Sci., 63, 2194-2211, https://doi.org/10.1175/JAS3746.1. 
_ 2012: Choosing a boundary layer parameterization for tropical cyclone modeling. Mon. Wea. Rev., 140, 1427-1445, https:// doi.org/10.1175/MWR-D-11-00217.1.

— and Y. Wang, 2001: The dynamics of boundary layer jets within the tropical cyclone core. Part II: Nonlinear enhancement. J. Atmos. Sci., 58, 2485-2501, https://doi.org/10.1175/ 1520-0469(2001)058<2485:TDOBLJ $>2.0 . C O ; 2$.

Li, S., and C. Miller, 2014: A study on the motion characteristics and their impact on the wind measurement post-processing of the GPS dropwindsonde. Part I: Effects of the wind-finding equations. Theor. Appl. Climatol., 117, 221-231, https://doi.org/ 10.1007/s00704-013-0962-5.

Lorsolo, S., J. A. Zhang, F. Marks Jr., and J. Gamache, 2010: Estimation and mapping of hurricane turbulent energy using airborne Doppler measurements. Mon. Wea. Rev., 138, 36563670, https://doi.org/10.1175/2010MWR3183.1.

Louis, J.-F., 1979: A parametric model of vertical eddy fluxes in the atmosphere. Bound.-Layer Meteor., 17, 187-202, https://doi.org/ 10.1007/BF00117978.

Markowski, P. M., and G. H. Bryan, 2016: LES of laminar flow in the PBL: A potential problem for convective storm simulations. Mon. Wea. Rev., 144, 1841-1850, https://doi.org/10.1175/ MWR-D-15-0439.1.

Marks, F. D., Jr., and R. A. Houze Jr., 1987: Inner core structure of Hurricane Alicia from airborne Doppler radar observations. J. Atmos. Sci., 44, 1296-1317, https://doi.org/10.1175/15200469(1987)044<1296:ICSOHA > 2.0.CO;2.

— - _ - and J. F. Gamache, 1992: Dual-aircraft investigation of the inner core of Hurricane Norbert. Part I: Kinematic structure. J. Atmos. Sci., 49, 919-942, https://doi.org/10.1175/15200469(1992)049<0919:DAIOTI >2.0.CO;2.

_ P. G. Black, M. T. Montgomery, and R. W. Burpee, 2008: Structure of the eye and eyewall of Hurricane Hugo (1989). Mon. Wea. Rev., 136, 1237-1259, https://doi.org/10.1175/2007MWR2073.1.

Morrison, H., G. Thompson, and V. Tatarskii, 2009: Impact of cloud microphysics on the development of trailing stratiform precipitation in a simulated squall line: Comparison of oneand two-moment schemes. Mon. Wea. Rev., 137, 991-1007, https://doi.org/10.1175/2008MWR2556.1.

Nolan, D. S., R. Atlas, K. T. Bhatia, and L. R. Bucci, 2013: Development and validation of a hurricane nature run using the joint OSSE nature run and the WRF Model. J. Adv. Model. Earth Syst., 5, 382-405, https://doi.org/10.1002/jame.20031.

- J. A. Zhang, and E. W. Uhlhorn, 2014: On the limits of estimating the maximum wind speeds in hurricanes. Mon. Wea. Rev., 142, 2814-2837, https://doi.org/10.1175/MWR-D-13-00337.1.

—, N. A. Dahl, G. H. Bryan, and R. Rotunno, 2017: Tornado vortex structure, intensity, and surface wind gusts in largeeddy simulations with fully developed turbulence. J. Atmos. Sci., 74, 1573-1597, https://doi.org/10.1175/JAS-D-16-0258.1.

OFCM, 2017: National Hurricane Operations Plan. NOAA/U.S. Dept. of Commerce Rep. FCM-P12-2017, 185 pp., http://www. ofcm.gov/publications/nhop/FCM-P12-2017.pdf.

Powell, M. D., P. P. Dodge, and M. L. Black, 1991: The landfall of Hurricane Hugo in the Carolinas: Surface wind distribution. Wea. Forecasting, 6, 379-399, https://doi.org/10.1175/15200434(1991)006<0379:TLOHHI > 2.0.CO;2.

—, E. W. Uhlhorn, and J. D. Kepert, 2009: Estimating maximum surface winds from hurricane reconnaissance measurements. Wea Forecasting, 24, 868-883, https://doi.org/10.1175/2008WAF2007087.1.

Richter, D. H., and D. P. Stern, 2014: Evidence of spray-mediated air-sea enthalpy flux within tropical cyclones. Geophys. Res. Lett., 41, 2997-3003, https://doi.org/10.1002/2014GL059746.
— , R. Bohac, and D. P. Stern, 2016: An assessment of the flux profile method for determining air-sea momentum and enthalpy fluxes from dropsonde data in tropical cyclones. J. Atmos. Sci., 73, 2665-2682, https://doi.org/10.1175/JAS-D-15-0331.1.

Rogers, R., and Coauthors, 2017: Rewriting the tropical record books: The extraordinary intensification of Hurricane Patricia (2015). Bull. Amer. Meteor. Soc., 98, 2091-2112, https://doi.org/ 10.1175/BAMS-D-16-0039.1.

Rotunno, R., Y. Chen, W. Wang, C. Davis, J. Dudhia, and G. J. Holland, 2009: Large-eddy simulation of an idealized tropical cyclone. Bull. Amer. Meteor. Soc., 90, 1783-1788, https:// doi.org/10.1175/2009BAMS2884.1.

Stern, D. P., and F. Zhang, 2013: How does the eye warm? Part I: A potential temperature budget analysis of an idealized tropical cyclone. J. Atmos. Sci., 70, 73-90, https://doi.org/10.1175/ JAS-D-11-0329.1.

, G. H. Bryan, and S. D. Aberson, 2016: Extreme low-level updrafts and wind speeds measured by dropsondes in tropical cyclones. Mon. Wea. Rev., 144, 2177-2204, https://doi.org/10.1175/ MWR-D-15-0313.1.

Sullivan, P. P., J. C. McWilliams, and C.-H. Moeng, 1994: A subgrid-scale model for large-eddy simulation of planetary boundary-layer flows. Bound.-Layer Meteor., 71, 247-276, https://doi.org/10.1007/BF00713741.

Uhlhorn, E. W., and D. S. Nolan, 2012: Observational undersampling in tropical cyclones and implications for estimated intensity. Mon. Wea. Rev., 140, 825-840, https://doi.org/10.1175/ MWR-D-11-00073.1.

Wakimoto, R. M., H. V. Murphey, E. V. Browell, and S. Ismail, 2006: The "triple point" on 24 May 2002 during IHOP. Part I: Airborne Doppler and LASE analyses of the frontal boundaries and convection initiation. Mon. Wea. Rev., 134, 231-250, https://doi.org/10.1175/MWR3066.1.

Wang, J., J. Bian, W. O. Brown, H. Cole, V. Grubišić, and K. Young, 2009: Vertical air motion from T-REX radiosonde and dropsonde data. J. Atmos. Oceanic Technol., 26, 928-942, https://doi.org/10.1175/2008JTECHA1240.1.

Worsnop, R. P., G. H. Bryan, J. K. Lundquist, and J. A. Zhang, 2017a: Using large-eddy simulations to define spectral and coherence characteristics of the hurricane boundary layer for wind-energy applications. Bound.-Layer Meteor., 165, 55-86, https://doi.org/10.1007/s10546-017-0266-x.

_ - J. K. Lundquist, G. H. Bryan, R. Damiani, and W. Musial, 2017b: Gusts and shear within hurricane eyewalls can exceed offshore wind turbine design standards. Geophys. Res. Lett., 44, 6413-6420, https://doi.org/10.1002/2017GL073537.

Wurman, J., and K. Kosiba, 2018: The role of small-scale vortices in enhancing surface winds and damage in Hurricane Harvey (2017). Mon. Wea. Rev., 146, 713-722, https://doi.org/10.1175/ MWR-D-17-0327.1.

Zhang, J. A., and E. W. Uhlhorn, 2012: Hurricane sea surface inflow angle and an observation-based parametric model. Mon. Wea. Rev., 140, 3587-3605, https://doi.org/10.1175/MWR-D11-00339.1.

— , F. D. Marks, M. T. Montgomery, and S. Lorsolo, 2011a: An estimation of turbulent characteristics in the low-level region of intense Hurricanes Allen (1980) and Hugo (1989). Mon. Wea. Rev., 139, 1447-1462, https://doi.org/10.1175/2010MWR3435.1.

, R. F. Rogers, D. S. Nolan, and F. D. Marks Jr., 2011b: On the characteristic height scales of the hurricane boundary layer. Mon. Wea. Rev., 139, 2523-2535, https://doi.org/10.1175/ MWR-D-10-05017.1. 